\title{
Short-sludge age EBPR process - Microbial and biochemical process characterisation during reactor start-up and operation
}

Valverde Pérez, Borja; Wágner, Dorottya Sarolta; Lóránt, Bálint ; Gülay, Arda; Smets, Barth F.; Plósz, Benedek G.

Published in:

Water Research

Link to article, DOI:

10.1016/j.watres.2016.08.026

Publication date:

2016

Document Version

Peer reviewed version

Link back to DTU Orbit

Citation (APA):

Valverde Pérez, B., Wágner, D. S., Lóránt, B., Gülay, A., Smets, B. F., \& Plósz, B. G. (2016). Short-sludge age EBPR process - Microbial and biochemical process characterisation during reactor start-up and operation. Water Research, 104, 320-329. https://doi.org/10.1016/j.watres.2016.08.026

\section{General rights}

Copyright and moral rights for the publications made accessible in the public portal are retained by the authors and/or other copyright owners and it is a condition of accessing publications that users recognise and abide by the legal requirements associated with these rights.

- Users may download and print one copy of any publication from the public portal for the purpose of private study or research.

- You may not further distribute the material or use it for any profit-making activity or commercial gain

- You may freely distribute the URL identifying the publication in the public portal 


\section{Short-sludge age EBPR process - microbial and biochem-}

2 ical process characterisation during reactor start-up and

3 operation

4 Borja Valverde-Pérez*, Dorottya S. Wágner, Bálint Lóránt, Arda Gülay, Barth F.

5 Smets, Benedek Gy. Plósz*

Department of Environmental Engineering (DTU Environment), Technical University of Denmark, Miljøvej, Building 115, DK-

\section{Abstract}

The new paradigm for used water treatment suggests the use of short solid reten-

13 tion times (SRT) to minimize organic substrate mineralization and to maximize resource

14 recovery. However, little is known about the microbes and the underlying biogeochemi-

15 cal mechanisms driving these short-SRT systems. In this paper, we report the start-up

16 and operation of a short-SRT enhanced biological phosphorus removal (EBPR) system

17 operated as a sequencing batch reactor (SBR) fed with preclarified municipal

18 wastewater, which is supplemented with propionate. The microbial community was ana-

19 lysed via 16S rRNA amplicon sequencing. During start-up (SRT=8 d), the EBPR was 
20 removing up to $99 \%$ of the influent phosphate and completely oxidized the incoming

21 ammonia. Furthermore, the sludge showed excellent settling properties. However, once

22 the SRT was shifted to 3.5 days nitrification was inhibited and bacteria of the Thiothrix

23 taxon proliferated in the reactor, thereby leading to filamentous bulking (sludge volume

24 index up to SVI=1100 mL/g). Phosphorus removal deteriorated during this period, like-

25 ly due to the out-competition of polyphosphate accumulating organisms (PAO) by sul-

26 phate reducing bacteria (SRB). Subsequently, SRB activity was suppressed by reducing

27 the anaerobic SRT from 1.2 day to 0.68 day, with a consequent rapid SVI decrease to $28 \sim 200 \mathrm{ml} / \mathrm{g}$. The short-SRT EBPR effectively removed phosphate and nitrification was 29 mitigated at SRT=3 days and oxygen levels ranging from 2 to $3 \mathrm{mg} / \mathrm{L}$.

\section{Keywords}

32 Enhanced biological phosphorus removal; microbial diversity; resource recovery; short 33 solid retention time activated sludge systems; sulphate reducers.

\section{$34 \quad 1$ Introduction}

35 The conventional activated sludge (CAS) process has been used for more than 100 years

36 for wastewater treatment (Schneider 2014). The process relies on a microbial communi-

37 ty formed mainly by bacteria able to remove organic carbon, nitrogen and phosphorus

38 from sewage. Current research, however, proposes a new approach whereby wastewater

39 components are recovered rather than destroyed (Verstraete et al., 2009). This new par- 
40 adigm suggests considering the wastewater treatment plant (WWTP) as a biorefinery,

41 whereby nutrients, energy, water, minerals or biopolymers can be separated and recov42 ered (Sheik et al., 2014).

43 Anaerobic digestion plays an important role in energy recovery from wastewater. One 44 option is to directly digest wastewaters with high organic carbon content (Shoener et 45 al., 2014). However, this alternative suffers from the loss of dissolved methane in the 46 effluent, which can be stripped to the atmosphere, thus contributing to climate change 47 (Verstraete et al., 2009). As an alternative, CAS can be combined with anaerobic diges48 tion, whereby the excess biomass wasted via solid retention time (SRT) control is an49 aerobically digested for biogas production. Operating CAS at long SRTs would lead to 50 the emission of large amounts of carbon dioxide in the aeration basins, thereby decreas51 ing the amount of organic carbon conveyed to the digester (Batstone et al., 2015). Short 52 SRT systems (i.e. SRT $<4$ days) have been proposed as a means to promote carbon as53 similation (i.e. microbial growth) and accumulation as stored polymers rather than oxi54 dation (Jimenez et al., 2015). The effluent of these systems are rich in nitrogen and 55 phosphorus, which can be recovered through physicochemical processes (e.g. ammonia 56 stripping or struvite precipitation, Verstraete et al., 2009) or via biological assimilation 57 (e.g. green microalgae cultivation, Shilton et al., 2012).

58 Enhanced biological phosphorus removal (EBPR) systems operated at short SRT can 59 integrate phosphorus upconcentration with energy recovery (Ge et al., 2013 and 2015). 60 Growth of polyphosphate accumulating organisms (PAO) in EBPR systems is promoted 61 by circulating the mixed liquor through a sequence of anaerobic and aerobic environ- 
62 ments (Mino et al., 1998). PAO release stored polyphosphate under anaerobic environ-

63 ments in the presence of bioavailable organic carbon, preferably volatile fatty acids 64 (VFA), which PAO take up and store as polyhydroxyalkanoates (PHA). PAO then use

65 the stored PHA under aerobic conditions as a carbon source for growth while accumu66 lating bioavailable phosphate in excess of their metabolic needs. Importantly, EBPR 67 systems can be used to create phosphorus rich effluent streams, optimal for P-recovery, 68 following two different strategies: either directly by partial diversion of the effluent 69 from the anaerobic reactor after phosphorus release (e.g. Barat and van Loosdrecht, 70 2006) or indirectly as a result of phosphorus release induced by anaerobic digestion of $71 \quad$ EBPR sludge (Yuan et al., 2012).

72 EBPR systems are a mature technology widely studied both in laboratory- and full-scale systems (Oehmen et al., 2007). The microbial communities in EBPR systems are also very well-known as most of the full scale plants have a similar microbial diversity with only the abundance of bacterial groups appearing to be plant specific (e.g. Nielsen et al., 2010; Albertsen et al., 2012; Mielczarek et al., 2013). However, most of these studies are based on long SRT system observations, where nitrification also occurs. Only a 78 few studies have focused on short-SRT EBPR systems (Mamais and Jenkis, 1992; 79 Brdjanovic et al., 1998; Ge et al., 2015; Valverde-Pérez et al., 2015 and 2016). Short80 SRT activated sludge systems, i.e. A-stage systems, have different communities than 81 those reported for CAS (González-Martínez et al., 2016; Meerburg et al., 2016). Whilst 82 the main microbial groups and factors that affect their abundance in A-stage systems 83 have been widely reported, we lack the same information for short-SRT EBPR systems. 
84 Only Ge et al. (2015) identified a novel PAO organism, belonging to the Comamona-

85 daceae family, which became dominant and drove P-removal in a short-SRT EBPR 86 treating abattoir wastewater. As a consequence, the available models, both ecological 87 and mathematical, may lack relevant bacterial groups to properly describe short-SRT 88 EBPR systems. Therefore, the main objectives of the present study are i) to describe the

89

90

91

92

93 start-up and operation of a short-SRT EBPR system ; ii) to assess the microbial community dynamics and identify operation strategies promoting effective process performance; iii) to identify the limitations of available biochemical process models and propose potential extensions to model the short-SRT EBPR process.

\section{Materials and Methods}

\subsection{Reactor description}

The EBPR system was a sequenced batch reactor (SBR) with $8 \mathrm{~L}$ volume, operated at hydraulic retention time (HRT) of $18 \mathrm{~h}$ and SRTs of 8, 3.5 and 3 days (operational conditions are summarized in Table 1). The initial operation sequence was 2 hours of anaerobic phase, 3 hours of aerobic phase and 1 hour of settling and idle phase. The reactor was fed during the first 2 minutes of the anaerobic phase. The SBR was fed with pre-clarified wastewater from Lundtofte WWTP (Kgs. Lyngby, DK) and spiked with synthetic wastewater supplemented with propionate and ortho-phosphate. 200 mg$\mathrm{COD} / \mathrm{ml}$ of propionate were dosed to avoid organic carbon limitation, simulating propionate dosing strategies based on primary sludge fermentation (Chanona et al., 2006). It should be noted that Lundtofte WWTP relies on chemical precipitation for phosphorus 
105 removal due to the low influent content on organic carbon. Phosphate was dosed to en106 sure that incoming phosphorus levels ranged between 6-10 mg-P/L. Oxygen was sup107 plied from a pressurized air-line and was manually controlled via needle valve manipu108 lation. The system was inoculated with biomass from a full-scale wastewater treatment 109 plant (Lynetten WWTP, Copenhagen, DK). The SBR operation was controlled using 110 LabView VI (National Instruments, Austin, USA).

\subsection{Analytical methods}

113 Process performance was assessed by monitoring bulk liquid concentrations of ammo114 nia, nitrite, nitrate, phosphate and sulphate using test kits supplied by Merck@ (USA) 115 after filtration through $0.2 \mu \mathrm{m}$ filter. Soluble and total COD were measured with Hach116 Lange $\odot$ test kits (USA). Dissolved oxygen (DO) and $\mathrm{pH}$ were monitored using FDO 117925 and SenTix 980 probes, respectively (WTW, Germany). Sludge volume index (SVI, 118 Ekama et al., 1997) was monitored on a daily basis. Total suspended solids (TSS) were 119 measured using glass fibre filter (Advantec $\odot$, USA) with a pore size of $0.6 \mu \mathrm{m}$ (APHA, 120 1995).

\subsection{Microbial analysis}

122 Quantitative polymerase chain reaction (qPCR) was carried out on all the extracted 123 DNA samples to determine the abundance of ammonia oxidizing bacteria (AOB) and 124 nitrite oxidizing bacteria (NOB, both Nitrobacter and Nitrospira), Thiothrix, Microthrix 125 parvicella and sulphate reducing bacteria (SRB). DNA was extracted according to Te- 
126 rada et al. (2010). Detailed protocols on DNA extraction and qPCR are included in the 127 supplementary information (SI-1).Quantitative fluorescence in situ hybridization 128 (qFISH) was performed as specified in Nielsen et al. (2009). Details of the qFISH pro129 tocol are shown in SI-2.

130 Community 16S rRNA genes were subject to partial PCR amplification as suggested by 131 Gülay et al. (2016) and amplicons were sequenced using the Illumina MiSeq platform at 132 the DTU Multi Assay Core Center (Copenhagen, DK). Bioinformatic approaches from 133 Gülay et al. (2016) were applieded in this study. Canonical correspondence analysis

134 (CCA) was used to examine the relationships between microbial community composi135 tion and system performance. Diversity of SRB was assessed via phylogenetic analysis 136 of clone libraries of genes involved in dissimilatory sulphite reductase: $d s r A$ (Ben-Dov 137 et al., 2007) and dsrB ( Geets et al., 2006). Further details can be found in SI-3.

\section{Results and discussion}

\subsection{Reactor performance}

140 The SBR system performance during the 190 days of operation is shown in Fig.1. Dur141 ing the operation at SRT 8 days (first 50 days), temperature varied between 16 and 19 $142{ }^{\circ} \mathrm{C}$, DO in the aerobic phase was always above $2 \mathrm{mg} / \mathrm{L}$ and $\mathrm{pH}$ ranged between 7.5 and 143 8. Under these conditions ammonia was fully oxidized. All non-discharged nitrate was 144 fully denitrified in the consecutive cycle (i.e. initial nitrate concentration up to 10 mg145 N/L; Fig. 1A). Nitrogen removal varied between $75 \%$ and 91\%. Phosphorus was effec- 
146 tively removed and effluent concentrations were always below $1 \mathrm{mg}-\mathrm{P} / \mathrm{L}$ (Fig. 1B). The 147 phosphorus removal varied between 80 and 98\% (Fig. 1D). Phosphate concentration at 148 the end of the anaerobic phase dropped from $28 \mathrm{mg}-\mathrm{P} / \mathrm{L}$ the first day down to $24 \mathrm{mg}-$ $149 \mathrm{P} / \mathrm{L}$ after day 10, ranging from that day between 20 and $25 \mathrm{mg}-\mathrm{P} / \mathrm{L}$ (Fig. 1B). Striking150 ly, phosphorus removal was poor (about $70 \%$ of phosphate removal) only during the 151 first week, when phosphate at the end of the anaerobic phase was highest. During that 152 period, most of the influent COD was removed in the anaerobic phase, whilst only 1 to $15310 \mathrm{mg}-\mathrm{COD} / \mathrm{L}$ were further removed along the aerobic phase (Fig. 1C). Likely, the ex154 tent of the anaerobic phase led initially to residual phosphorus release, due to PAO hy155 drolysing stored polyphosphate for maintenance under anaerobic conditions in absence 156 of available COD (Maurer and Gujer, 1995). Under aerobic conditions PAO could not 157 take up the released phosphorus, as they were limited by stored PHA. After an adapta158 tion period of 1 week, the internal PHA and polyphosphate storage were balanced and 159 all anaerobically released phosphorus was taken up in the subsequent aerobic phase. 160 TSS in the reactor decreased from $5 \mathrm{~g} / \mathrm{L}$ to $1.8 \mathrm{~g} / \mathrm{L}$ after 10 days, and then, depending 161 on the influent COD, varied between 1.5 and $2 \mathrm{~g} / \mathrm{L}$ (Fig. 1F). The SVI was consistently 162 below $90 \mathrm{~mL} / \mathrm{g}$ (Fig. 1E), indicating good sludge settling behaviour. Despite the fact 163 that nitrate was present at the beginning of the anaerobic phase, the SRT was high 164 enough to avoid PAO out-competition.

165 On day 50, the system SRT was reduced to 3.5 days. DO, temperature and $\mathrm{pH}$ remained 166 in the same ranges as in the previous period. Over a period of 28 days, nitrate in the ef167 fluent decreased, while nitrite accumulated as high as $4 \mathrm{mg}-\mathrm{N} / \mathrm{L}$ (end of phase A, Fig. 
168 1A). Nitrite accumulation suggests that nitrite oxidizing bacteria (NOB) were phased 169 out of the system, while ammonia oxidizing bacteria (AOB) were still active. Nitrite 170 was fully denitrified, thereby leading to a nitrogen removal higher than $80 \%$. At tem171 peratures ranging between 16 and 19 degrees, AOB apparently grew faster than NOB, 172 and the 3.5 days SRT was insufficient to keep NOB in the reactor (Hellinga et al., 173 1998). Phosphate removal was comparable to the previous period, ranging between 83 174 and $99 \%$ (Fig. 1D). Phosphate in the effluent was kept below 1 mg-P/L (Fig. 1B), ex175 cept for 2 days when the influent phosphate concentration was comparably higher (ap176 prox. $15 \mathrm{mg}-\mathrm{P} / \mathrm{L}$ ). Phosphate concentration at the end of the anaerobic phase (Fig. 1B) 177 decreased to $18 \mathrm{mg}-\mathrm{P} / \mathrm{L}$ towards the end of this period. COD was also removed mainly 178 in the anaerobic phase. However, increasing amounts of COD were bleeding through to 179 the aerobic phase, thereby supporting aerobic heterotrophic growth (up to $97 \mathrm{mg}$ $180 \mathrm{COD} / \mathrm{L}$ when the influent TCOD was $620 \mathrm{mg}-\mathrm{COD} / \mathrm{L}$, Fig. 1C). TSS concentration 181 range decreased to 1-1.5 g/L. During this period, the SVI increased and ranged between 18298 and $130 \mathrm{~mL} / \mathrm{g}$ (Fig. 1E), indicating relatively good sludge settling properties.

183 The aerobic phase length was reduced from 3 to 2.5 hours for 5 days (phase B), thus 184 reducing the aerobic SRT from 1.75 to 1.45 days, to effectively wash-out AOB. Nitrite 185 concentrations immediately decreased and effluent ammonia concentration started to 186 increase. As a result of the shorter aerobic phase phosphorus removal also deteriorated 187 decreasing to a minimum value of $36 \%$ (Fig. 1D). Furthermore, the SVI increased up to $188157 \mathrm{ml} / \mathrm{g}$ by the end of this period (Fig. 1E). 
189 Although the reduced aerobic phase led to ammonia accumulation in the SBR, phospho190 rus removal was comparably low, likely due to a too short aerobic SRT for PAO 191 growth, and the 3 hours aerobic phase was restored and kept for another 26 days (phase 192 C). During the first week of this period, air supply failure led to oxygen concentrations 193 during the aerobic phase ranging from 0.5 to $2 \mathrm{mg} / \mathrm{L}$. Ammonia was kept within the 194 same range as in the previous 5 days, whilst phosphate removal was restored to a range 195 of 55-80\%. However, SVI increased up to a maximum of $343 \mathrm{ml} / \mathrm{g}$, representative of 196 filamentous bulking, as consequence of comparably low oxygen levels in the aerobic 197 phase (Martins et al., 2003). Once the oxygen level was restored above $2 \mathrm{mg} / \mathrm{L}$ we ex198 pected that phosphate removal and SVI were restored. However, SVI further increased 199 to a maximum of $1100 \mathrm{~mL} / \mathrm{g}$, showing high variability along consecutive days (e.g. var200 iations of about $250 \mathrm{~mL} / \mathrm{g}$ per day). Parallel, phosphorus removal decreased down to a 201 minimum of 23\%, coincident with the maximum SVI. The decrease in PAO activity was 202 also reflected by much lower phosphate concentrations at the end of the anaerobic 203 phase, ranging from 7.4 to 13 mg-P/L (Fig. 1B). Since high oxygen levels are reported 204 to hinder filamentous bulking (Martins et al., 2003), oxygen was subsequently main205 tained higher than $4.5 \mathrm{mg} / \mathrm{L}$ (from day 102 to 109), without any positive impact on the 206 system performance.

207 Sulphate reduction during the anaerobic phase was 30\% at the end of period C (Fig. 208 S16), suggesting that SRB were active in the EBPR. Previous studies have demonstrat209 ed the coexistence of sulphate reducing bacteria (SRB), Thiothrix, PAO and ordinary 210 heterotrophs in EBPR systems (Yamamoto-Ikemoto et al., 1996). Thiothrix, a filamen- 
211 tous bacterium that contributes to filamentous bulking (Tandoi et al., 2006), can effec-

212 tively grow on the reduced sulphur compounds produced by the SRB under aerobic 213 conditions. To mitigate the growth of SRB, the anaerobic SRT was decreased from 1.2 214 days to 0.88 days for 23 days (phase D). SVI decreased to $363 \mathrm{ml} / \mathrm{g}$ within two weeks. 215 Phosphate removal was partially restored, ranging from 55 to 77\%. During the aerobic 216 phase, to prevent the growth of other filamentous bacteria, DO was kept higher than 4.5 $217 \mathrm{mg} / \mathrm{L}$. Ammonia was the main nitrogen form in the effluent, although nitrite ranged be218 tween 0.1 and $3.2 \mathrm{mg}-\mathrm{N} / \mathrm{L}$.

220 Given the positive system response to the reduction of anaerobic SRT, we further re221 duced it to 0.68 days for the next 24 days (phase E). Within this period, after one week 222 of stable and high SVI (413-568 mL/g) and moderate phosphorus removal (58-70\%), 223 the SVI progressively decreased to a minimum of $123 \mathrm{ml} / \mathrm{g}$. Phase E was characterized 224 by limited filamentous bulking, with a SVI ranging between 123 and $213 \mathrm{ml} / \mathrm{g}$, and a 225 sharp increase in phosphorus removal, restored to 85-99\%. Indeed, after the first week, 226 the phosphate level in the effluent was below $0.8 \mathrm{mg}-\mathrm{P} / \mathrm{L}$. Sulphate reduction correlated 227 relatively well $\left(\mathrm{R}^{2}=0.65\right.$, Fig. $\left.\mathrm{S} 16\right)$ with phosphate removal, suggesting that as a conse228 quence of the sulphate reduction the PAO may have been outcompeted by SRB.

230 The phosphate concentration at the end of the anaerobic phase was as high as 18-24 mg231 P/L. Sulphate reduction was not observed from day 120 onward. DO was kept higher 
232 than $4.5 \mathrm{mg} / \mathrm{L}$ to prevent bulking due to other filaments. However, AOB activity re233 turned, and nitrite was detected during the aerobic phase, reaching a maximum of 10.3 234 mg-N/L, which could potentially lead to phosphorus uptake inhibition. TSS varied be235 tween 0.5 and $1.2 \mathrm{~g} / \mathrm{L}$ in this period. Towards the end of this period, the temperature 236 range slightly increased to $17-21^{\circ} \mathrm{C}$.

237 Finally, at day 150 the SRT was lowered to 3 days to repress AOB activity. Oxygen 238 level was kept between 2 and $3 \mathrm{mg} / \mathrm{L}$, sufficiently high to support P uptake by PAO, as 239 suggested by previous model-based studies (Valverde-Pérez et al., 2015). As shown in 240 Fig. 1A, nitrite at the end of the anaerobic phase was reduced, whilst ammonia in241 creased again. Any nitrogen removal, about $40 \%$ of the influent ammonia, observed at 242 this stage was likely due to assimilation, as neither nitrite nor nitrate were observed in 243 the effluent. Both, phosphorus removal kept high (85-99\%) and SVI ranged between 90 244 and $290 \mathrm{ml} / \mathrm{g}$. The SBR was kept stable at SRT=3 days, DO 2-3 $\mathrm{mg} / \mathrm{L}$ and anaerobic 245 and aerobic phase lengths of 70 minutes (i.e. anaerobic SRT of 0.58 days) and 3 hours 246 (i.e. 1.5 day of aerobic SRT, above the minimum aerobic SRT reported by Brdjanovic et 247 al., 1998), respectively, for 35 days (> 3 SRTs).

\subsection{Variation in microbial community composition and} diversity

250 Illumina MiSeq sequencing generated 1,745,605 raw assembled reads from 21 samples 251 with an average length of $420 \mathrm{bp}$. A total of 1,098,943 (63\%) sequences passed quality 252 checks, and clustered across 167,622 OTUs, defined at 97\% sequence similarity (Fig. 
253 S1). The sample taken at day 30 was excluded from further analysis due to the low 254 number of sequences available in the sample library. High-quality sequences were nor255 malized by rarefying to 11,940 sequences per sample for further diversity and taxonom256 ic comparisons.

257 In Fig. 2, the distribution of the most abundant taxa is shown at the order level. It is 258 clear that from day 50, when the system SRT was reduced, the Thiothrichales order in259 creased in abundance, mostly comprising Thiothrix spp. This increase continued during 260 the bulking event. From a relative abundance of 50\% onward (based on sequencing 261 analysis), the relative Thiothrix abundance strongly correlated with the extent of fila262 mentous bulking (characterised using SVI as surrogate $-\mathrm{R}^{2}=0.92$; Fig. S17). From day 263101 to 109 the anaerobic SRT was reduced to 0.88 day. These conditions resulted in a 264 reduction of Thiothrix abundance. However, no obvious patterns in known SRB taxa 265 (Fig. S11) - presumed to be responsible for Thiothrix growth by reducing sulphate to 266 sulphide - were found. After SVI correction and phosphorus removal restoration, the 267 microbial diversity became similar to the one by the end of the SRT=8-day phase based 268 on the H index (Fig. 3 and Fig. S2). Similar trends were confirmed via qPCR quantifica269 tion (Fig. S10).

271 Rhodocyclales were relatively abundant during good phosphorus removal and were only 272 displaced during filamentous bulking. Rhodocyclales include Accumulibacter phospha273 tis, which is believed to be the main driver of phosphorus removal in EBPR systems 274 (Oehmen et al., 2007). However, Accumilibacter abundance was very low (<1\%) com- 
275 pared to previous studies (Fig. S4, Nielsen et al., 2010). Nevertheless, Rhodocyclales 276 positively correlated with phosphate removal suggesting that members other than Ac277 cumulibacter could have been involved in phosphorus removal (Fig. 6), e.g., 278 Dechloromonas related PAO (Lv et al., 2015). However, qFISH analysis revealed high279 er abundance of Accumulibacter than that indicated by the sequencing data, especially 280 towards the end of the operational period (up to $18 \%$ of total bacteria, Fig. S13). This is 281 a major difference compared to the study by Ge et al. (2015), who did not find Accumu282 libacter in the short-SRT EBPR. Similar to the A-stage systems, it may be the case that 283 microbial communities are case specific, contrary to CAS, which contains a core com284 munity of abundant microorganisms (González-Martínez et al., 2016). Tetrasphaera 285 remained low during the operational period (Fig. S4 and S13).

286 Saprospriales, Flavobacteriales and Burkholderiales are heterotrophic microorganisms 287 that appeared at relatively high abundance along the operation of the reactor. In the case 288 of Burkholderiales the considerable abundance could be a consequence of their extreme 289 nutritional versatility and adaptability to different environmental conditions. Burkhold290 eriales are often found in EBPR systems (Sadaie et al., 2007), and include Comamona291 daceae, which have been reported as putative PAO (Ge et al., 2015). However, abun292 dance of Comamonadaceae did not follow the trends on phosphorus removal (Fig. S5). 293 Saprospriales are specialized in the hydrolysis of proteins and are abundant in conven294 tional EBPR systems (Nielsen et al., 2012), but also in short-SRT EBPR systems (Ge et 295 al., 2015). Finally, Flavobacteriales are rather nutritionally restricted, with the ability to 296 consume glucose and very few other carbon compounds. Nevertheless, they can hydro- 
297 lyze several biopolymers and particulate products from bacterial decay (Kircham 2012). 298 They have also been found in Danish EBPR systems (Albertsen et al., 2012): they might 299 grow little in the actual treatment plant but are present due to their high abundance in 300 the influent sewage (Saunders et al., 2016). The higher abundance of Flavobacteriales 301 in the short-EBPR system compared to full scale EBPR (7\% vs 1\% reported by Saun302 ders et al., 2016) suggests that microbial composition of short-SRT EBPR communities 303 is more closely related to the influent microbial communities, as suggested for the A304 stage systems (González-Martínez et al., 2016).

305 Following the trends in performance, NOB were washed out from the system from the 306 onset of SRT reduction (Fig. S8). AOB followed a similar trend, but their abundance in 307 the amplicon libraries was one order of magnitude lower. Targeted qPCR analysis was 308 conducted to quantify Nitrosomonas, Nitrobacter and Nitrospira. AOB guild ranged 309 between 3.6-13.6 \% while Nitrospira ranged from 1 to $4.3 \%$ (Fig. S9, Table S12).

310 Despite their low abundance (Fig. S7 and S11), the role of SRB is also worth mention311 ing. Our results suggest that SRB can reduce sulphate at very low abundance $(<0.15 \%)$, 312 as was the case for data presented by Pester et al. (2010). According to Fig. 3, the genus 313 Desulfarculus is strongly and negatively correlated with phosphorus removal. This is in 314 agreement with the process performance of the SBR, which showed very poor phospho315 rus removal when sulphate reduction was relatively high (Fig. SI-16). Desulfarculus is a 316 completely carbon oxidizing SRB, which is able to consume a wide range of organic 317 substrates. Furthermore, it is oxygen tolerant so it can survive during the aerobic phase 318 (Sun et al., 2010). Desulfuromonas also correlated negatively with phosphorus removal 
319 (Fig. 3). Similarly to Desulfarculus, these bacteria can also oxidize propionate and ace320 tate to carbon dioxide. However, Desulfuromonas is only able to reduce sulphur and not 321 sulphate (Pfennig and Biebl, 1976).

323 Finally, GAO were barely detected in the libraries, indicating low abundance $(<0.1 \%)$ 324 for both Competibacter- and Defluviicoccus- related GAO (Fig. S6). Despite the im325 portance of these organisms in EBPR systems, they may have been effectively outcom326 peted from the SBR due to the dosing strategy (propionate cannot be consumed by 327 Competibacter) and the relatively low temperatures and high $\mathrm{pH}$, which give competi328 tive advantages to PAO over GAO (López-Vázquez et al., 2009). qFISH revealed higher 329 abundance of both Competibacter and Defluviicoccus, but always below 3.8\% and 1\%, 330 respectively (Fig. S12, Table S12). Other putative GAO, such as Micropruina (Kong et 331 al., 2001), were also present at low abundance ( $<0.1 \%$, Fig. S6).

\subsection{Discrepancies between quantification methods}

There is a discrepancy between the results from the amplicon sequencing and data estimated via qPCR or qFISH (Tables S11 and S12). For example, the abundance of Nitrosomonas or Nitrospira determined via sequencing is comparably lower than the qPCR estimate, as was observed by Pellicer-Nácher et al. (2014). A plausible explanation is related to the understimation of low abundant bacteria by the amplicon sequencing method. González et al. (2012) demonstrated that the amplification via PCR of low abundant bacteria DNA is considerably less efficient than the amplification of highly 
340 abundant bacteria DNA, thus leading to the overestimation of highly abundant microbi-

341 al groups. This is clearly the case for Thiothrix population, which has been underesti342 mated via sequencing at abundances below 5\% and overestimated in other cases (Table 343 S11 and S12). When comparing sequencing and qFISH results other factors should be 344 taken into account, such as DNA extraction efficiency, which may introduce significant 345 bias into PCR-based estimates (Kim et al., 2013). As an example, Albertsen et al. 346 (2012) reports high discrepancy between qFISH based and sequencing based results for 347 Gram positive bacteria (e.g. Tetrasphaera or Microthrix parvicella) presumably, due to 348 innefficient DNA extraction. However, they found a good agreement between both data 349 sets for Competibacter or Accumulibacter bacteria, which suggests that discrepancies in 350 our study may have a different origin. Analyzing the correspondence between qFISH 351 probes targeting Accumulibacter, it can be seen that they detect low abundance within 352 the sequences amplified by the PCR. Therefore, the sequencing results may be biased 353 by the universal primer selection (Hong et al., 2009). To get a better overview of the 354 microbial diversity it is recommended to combine different techniques, preferably com355 bining methods that rely on DNA extraction (e.g. PCR based methods) with tools that 356 do not require this step (e.g. qFISH). short SRT EBPR systems

359 At SRT=3.5 days, NOB were effectively washed out from the system, thus leading to 360 nitrite accumulation (e.g. from day 50 to day 55). Likely, the operation of the EBPR 
361 system at an aerobic SRT=1.75 days, combined with relatively high oxygen levels, had 362 a detrimental effect over Nitrospira sp. and not Nitrosomonas, thus leading to nitrite 363 rather than nitrate accumulation (Regmi et al., 2014). Additionally, high ammonia lev364 els at pH close to 8, e.g. phase E (Fig. 1A), may have inhibited NOB activity (Chandran 365 and Smets, 2000). Nitrite accumulation in this period could potentially lead to the inhi366 bition of PAO activity. Nitrite has been reported as a potent inhibitor for P-uptake under 367 both anoxic and aerobic conditions (e.g. $0.5 \cdot 10^{-3} \mathrm{mg}-\mathrm{N}-\mathrm{HNO}_{2} / \mathrm{L}$ lead to $50 \%$ anabolic 368 activity inhibition; Meinhold et al., 1999; Pijuan et al., 2010). Indeed, previous experi369 mental runs at SRT=4-5 d lead to the wash out of PAO likely due to nitrite accumula370 tion in the aerobic phase. Therefore, these operational conditions were not tested in this 371 study (Valverde-Pérez et al., 2015b). Surprisingly, nitrite presence did not negatively 372 affect PAO performance. On the one hand, at the observed $\mathrm{pH}$ levels (ranging between 3737.5 and 8), the concentration of free nitrous acid (FNA), which is the true inhibitor of 374 PAO activity, was varying between $0.8 \cdot 10^{-3}$ and $0.2 \cdot 10^{-3} \mathrm{mg}-\mathrm{N} / \mathrm{L}$, i.e., below the inhibi375 tion levels reported by Pijuan et al. (2010). On the other hand, PAO could have adapted 376 to the presence of nitrite (Wang et al., 2014). Additionally, if AOB or NOB are not ef377 fectively phased out at SRTs ranging from 4 to 6 days, PAO may be outcompeted by 378 denitrifying heterotrophs due to substrate competition during the anaerobic phase 379 (Guerrero et al., 2011). This has been demonstrated through dedicated simulation stud380 ies (Valverde-Pérez et al., 2015). Based on the stoichiometry reported on the activated 381 sludge model 2d (ASM2d, Henze et al., 1999), about 30\% of the influent COD was con- 
sumed by denitrifying bacteria, leaving enough COD (about 30mg-COD L-1 per cycle) available to replenish the PHA storage from PAO.

If nitrifiers are effectively washed out of the reactor, at the beginning of the anaerobic phase there is no nitrate nor nitrite. The fully anaerobic phase could then promote sulphate reduction by SRB if sufficient sulphate is available. SRB were present in low abundance along the study (Fig. S7 and S11) but sulphate reduction was not observed when nitrate was recycled to the beginning of the anaerobic phase. SRB have been described as tolerant bacteria, which can grow even in the absence of sulphate, showing high metabolic flexibility (Plugge et al., 2011). Furthermore, SRB have a wide variety 391 of protection strategies that let them survive in adverse environments, such as those 392 characterized by aerobic or high salinity conditions (Zhou et al., 2011). Hence, SRB 393 could use their capabilities to survive in the reactor under unfavourable conditions and 394 only actively reduced sulphate once $\mathrm{NO}_{\mathrm{x}}$ were not present at the beginning of the anaer395 obic phase of the SBR (i.e. when most of the propionate is available for their growth). 396 Alternatively, SRB could actively reduce sulphate in the presence of nitrate. However, 397 due to the prevalence of nitrate, reduced sulphur coumpounds could be oxidized back 398 via denitrification (Jensen et al., 2009). SRB may support the growth of Thiothrix by 399 producing sulphur reduced compounds available for their growth under aerobic condi400 tions. Thiothrix is an obligate aerobic mixotroph, which frequently appears in EBPR 401 reactors treating industrial wastewaters (Nielsen et al., 2010). However, the high abun402 dance found in this study has been only previously found in systems where SRB pro403 vided them with enough sulphur reduced chemicals (Yamamoto-Ikemoto et al., 1991, 
404 1994, 1996). Thiothrix can significantly deteriorate settling properties of activated 405 sludge at relatively high relative abundance (Fig. S17), but do not seem to be related to 406 poor phosphorus removal (Fig. 3).

407 SRB can interact with PAO in different ways. SRB produce sulphide, which can inhibit 408 phosphorus release, thereby reducing it to $50 \%$ at concentrations of $60 \mathrm{mg}-\mathrm{H}_{2} \mathrm{~S} / \mathrm{L}$ (Saa 409 et al., 2013). Since phosphorus release is hindered under anaerobic conditions, PAO 410 cannot grow under aerobic conditions, thus leading to their wash out from the system. 411 Additionally, SRB take up organic carbon under anaerobic conditions. The most com412 mon SRB in wastewater treatment systems are incomplete carbon oxidizers, such as 413 Desulfobulbos or Desulfovivbrio (Hao et al., 2014), both found via phylogenetic analy414 sis (Fig. S14 and S15). The end product of incomplete oxidation process is acetate, 415 which is finally available for other bacteria, such as PAO (Yamamoto-Ikemoto et al., 416 1996). Therefore, there is limited competition for carbon between incomplete oxidizing 417 SRB and PAO. Other SRB, like Desulfarculus in this study, are able to completely oxi418 dize organic carbon to carbon dioxide (Hao et al., 2014). Therefore, this second type of 419 SRB may compete with PAO for organic carbon in the anaerobic phase, thus leading to 420 incomplete phosphorus removal, as suggested by Fig. 3. To further support this hypoth421 esis, the COD consumption was estimated, based on stoichiometric coefficients from 422 literature (Yamamoto-Ikemoto et al., 1996), for the day with maximum reported SVI 423 (SVI=1100 ml/g; sulphate reduction of 30\%). About 35\% of the influent COD was con424 sumed for sulphate reduction. Surprisingly, sulphate reduction stopped before all COD 425 was consumed, as comparably high COD levels and sulphate were detected at the end of 
426 the anaerobic phase along the bulking event (Fig. 1C). Presumably, VFA, propionate in 427 this case, were taken up first by SRB or PAO, while the rest of the available COD needs 428 to be hydrolysed or fermented before it can be consumed by PAO and SRB. Since the 429 specific uptake rate of propionate by SRB is about 3 times higher than for PAO (calcu430 lations based on Henze et al., 1999 and Cassidy et al., 2015 are reported in SI-7), SRB 431 could outcompete PAO for VFA uptake at the beginning of the anaerobic phase. Sul432 phate reduction may stop due to self-inhibition of SRB with the produced sulphide 433 (Reis et al., 1992). Additionally, sulphide may also inhibit fermentative microorgan434 isms, thereby limiting the production of more easily biodegradable substrate available 435 for oxidation by SRB (McCartney and Oleszkiewicz, 1991). Several studies suggest that 436 sulphide is a strong inhibitor of microbial growth at relatively low $\mathrm{pH}$ levels, but others 437 observed that $\mathrm{pH}$ effect on inhibition was negligible (Chen et al., 2014). The COD 438 bleeding through from the anaerobic phase could enhance the growth of Thiothrix along 439 the aerobic phase (Vaiopoulou et al., 2007). Therefore, the most plausible explanation 440 for the inactivation of PAO is a combination of substrate competition at the beginning 441 of the cycle and inhibition due to sulphide. This could be the cause of poor phosphorus 442 removal of other systems where SRB coexisted with PAO (Yamamoto-Ikemoto et al., 443 1991; Vaiopoulou et al., 2007). In this study, SRB activity was controlled by manipulat444 ing anaerobic SRT. When the anaerobic phase length was 2 hours, corresponding to 1.2 445 days - calculation without accounting for the 1 hour non aerated settling phase - those 446 SRB with a growth rate higher than 1 day $^{-1}$ could grow in the reactor (Cassidy et al., 447 2015). Once sulphate reduction was avoided during the anaerobic phase, phosphorus 
448 removal was restored, further supporting this hypothesis. These findings are relevant to

449 those WWTPs located close to the coastline, where the sulphate content in wastewater 450 is expected to be high (van den Brand et al., 2015). This is the case for Lundtofte 451 WWTP, which is barely $5 \mathrm{~km}$ from the sea. A two-month sampling campaign was per452 formed to further verify this. Influent sulphate concentrations measured in the influent

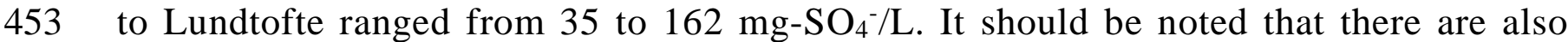
454 cases where the phosphorus and the sulphur cycle have been successfully combined, 455 such as the SANI process (Wu et al., 2014). Nevertheless, phosphorus removal in this 456 process is driven by microbes capable to oxidize sulphide rather than Accumulibacter 457 (Guo et al., 2016), which makes it non comparable to our study.

458 Interestingly, neither Competibacter nor Defluviicoccus seemed to affect phosphorus 459 removal during the operation. As stated before, the carbon source, propionate, dosed to 460 the system together with the relatively high $\mathrm{pH}$ and moderate temperature may have 461 outcompeted the GAO from the reactor (López-Vázquez et al., 2009). The low SRT 462 could also have contributed to the wash-out GAO. EBPR systems operated at SRT=3 463 days did not register instabilities due to the competition between GAO and PAO even at $46430^{\circ} \mathrm{C}$ (Whang and Park, 2006). Nevertheless, should Competibacter grow at low SRTs, 465 attention should be paid to the incomplete oxidizing SRB. Since they can produce ace466 tate as a final product, this may become available for Competibater, thereby making the 467 dosing strategies proposed in the literature unsuccessful (López-Vázquez et al., 2009). 468 Additionally, inhibition by sulphide may be another selective factor between PAO and 469 GAO, which should be subject of future study. 
470 The proposed ecological model, based on the interactions between microbiological 471 guildts found in this study, is shown in Fig.4.

\subsection{Sludge settling properties}

474

475

Poor settling may compromise effluent quality by increasing the TSS in the effluent of the plant, thereby compromising pathogen removal (Schuler and Jang, 2007). According to Fig. 3, Thiothrix was the main taxon affecting the settling properties. This is in agreement with previous studies where extreme filamentous bulking was provoked by Thiothrix (SVI>600 mg/L, Yamamoto-Ikemoto et al., 1991; Miyazato et al., 2006). As suggested by Fig. S17, there is linear correlation between Thiothrix abundance and SVI only beyond $50 \%$ relative abundance. The poor fitting at lower abundances can be a consequence of the synergic effect of a decrease in biomass density due to the coincident wash out of PAO, with filamentous bulking (Schuler and Jang, 2007). Since phosphorus uptake by PAO was hindered by SRB, the polyphosphate content in sludge was expected to be lower, thereby producing low density sludge. Low density sludge is more sensitive to filamentous bulking (Jassby et al., 2014), which could explain the highly dynamic SVI found between days 80 and 150. On the other hand, previous studies have shown poor correlation between filamentous bacteria abundance and SVI, suggesting as an alternative to look for correlations with the hindered settling model parameters (Wágner et al., 2015). Furthermore, Wágner et al. (2015) demonstrated that a specific filamentous bacteria (M. parvicella), can drive bulking regardless of other filamentous 
491 bacteria (e.g., Chloroflexi), prevailing at significantly higher abundance level. There492 fore, SVI dynamics found at relatively low abundance of Thiothrix could be driven by 493 other filaments which were much less abundant. As an example, filaments belonging to 494 the phylum Firminicutes, common filaments in EBPR systems (Mielczarek et al., 2012), 495 found at low abundance along the operation of the reactor, such as Thrichococcus $(\sim 1 \%$ 496 Fig. S3, Nielsen et al., 2009b), could affect the settling properties while Thiothrix were 497 not abundant. Strikingly, M. parvicella were found in low abundances $(<1 \%$ at SRT $<4$ 498 days). One plausible explanation is that these filaments are supressed at SRTs lower 499 than 5.7 days (Noutsopoulos et al., 2006).

500 Low SRT activated sludge systems are characterized by relatively unstable microbial 501 communities, which facilitate filamentous bacteria proliferation (Liao et al., 2006). Pre502 vious work has demonstrated that SBRs are more robust than continuous flow systems 503 operated under the same conditions (Liao et al., 2006; Valverde-Pérez, 2015). This 504 work shows how, through careful control of the oxygen level and anaerobic SRT, fila505 mentous bulking can be controlled. Since the SBR operation leads to substrate gradi506 ents, flock forming bacteria are promoted over filamentous bacteria, thereby reducing 507 the risk of filamentous bulking event (Tandoi et al., 2006).

\subsection{Relevance to available models}

509 The findings of this study point out several limitations of available models to describe 510 phosphorus removal in EBPR systems, both activated sludge models (ASM-2d, Henze

511 et al., 1999) and metabolic models (Oehmen et al., 2010). Indeed, the latter has focused 
512 on describing the competition between GAO and PAO for different substrates and under

513 different operational conditions (e.g. Carvalheira et al., 2014). Whilst this effort is very

514 valuable to model conventional EBPR systems, it seems incomplete when modelling 515 short SRT systems. The importance of the SRB in modelling anaerobic digestion pro516 cesses has already been acknowledged (Jeppsson et al., 2013), but, according to Fig. 4, 517 they should also be included in other process units across the WWTP. Otherwise, mod518 el-based optimization of EBPR systems may lead to model falsification (Sin et al., 519 2006).

520 Even though the reactor operation became stable after regulating the anaerobic SRT, the 521 SBR still run under moderate bulking conditions (i.e. SVI>200 ml/g). Low SRT systems 522 suffer from poor settling due to poor sludge flocculation (Meerburg et al., 2015). There523 fore, settling models should be improved by including time dependent parameters able 524 to capture the sludge properties dynamics (Jeppsson et al., 2013). Some efforts have 525 already been presented in the literature to reduce the uncertainty of settling parameters 526 due to filamentous bulking (Wágner et al., 2015), which up until now has been consid527 ered as a non-reducible uncertainty source (Belia et al., 2009).

\section{Conclusions}

529 This study describes the dynamics and successful start-up of a short-SRT EBPR system, 530 which is suitable for resource recovery, especially carbon and phosphorus. Our results 531 suggest that: 
- EBPR process can be run at a system SRT of 3 days, effectively removing phosphorus and organic carbon. SVI was relatively high (SVI 200ml/g), but stable.

- NOB were effectively removed from the reactor at SRT below 3.5 days (corresponding to 1.75 days aerobic SRT). AOB were phased out from the SBR by lowering the SRT down to 3 days (i.e. 1.5 days of aerobic SRT) and controlling the oxygen level lower than $3 \mathrm{mg} / \mathrm{L}$.

- Sulphate reduction was observed at SRT 3.5 days, producing sulphur reduced chemicals, which served as substrate for Thiothrix, thereby provoking filamentous bulking. SRB were shown to have a negative impact on phosphorus removal, although the inhibition mechanism could not be identified. SRB activity was suppressed by reducing the anaerobic SRT to 0.58 days and process performance was restored.

Models should include SRB related processes to properly address the competition between them and PAO. Furthermore, since bulking cannot be completely avoided, future research should address the inclusion of time varying parameters for settling models to properly track changes of or in sludge properties.

\section{Acknowledgement}

Borja Valverde-Pérez and Dorottya S. Wágner thank the Integrated Water Technology (InWaTech) project (http://www.inwatech.org) for the financial support. We would like to thank Ms. Lene Kirstejn Jensen and Dr. Marlene Mark Jensen for their assistance conducting the qPCR measurements and Dr. A. Gizem Mutlu and Dr. Aranud Dechesne for their guidance when conducting the qFISH analysis. 


\section{References}

554 Albertsen, M., Hansen, L.B.S., Saunders, A.M., Nielsen, P.H., Nielsen, K.L., 2012. A 555 metagenome of a full-scale microbial community carrying out enhanced biological 556 phosphorus removal. The ISME Journal, 6, 1094-1106.

558 APHA, American Public Health Association. Standard Methods for the Examination of 559 Water and Wastewater. Washington DC, 1995.

561 Barat, R., van Loosdrecht, M.C.M., 2006. Potential phosphorus recovery in a WWTP 562 with the BCFS process: interactions with the biological process. Water Research, 40, $563 \quad 3507-3516$.

564

565 Batstone, D.J., Hülsen, T., Mehta, C.M., Keller, J., 2015. Platforms for energy and nu566 trient recovery from domestic wastewater: A review. Chemosphere, 140, 2-11.

568 Belia, E., Amerlinck, Y., Benedetti, L., Johnson, B., Sin, G., Vanrolleghem, P.A., 569 Gernaey, K.V., Guillot, S., Neumann, M.B., Rieger, L., Shaw, A., Villez, K., 2009. 570 Wastewater treatment modelling: dealing with uncertainties. Water Science and Tech571 nology, 60(8), 1929-1941. 
573 Ben-Dov, E., Brenner, A., Kushmaro, A., 2007.Quantification of sulfate-reducing bacte574 ria in industrial wastewater, by real-time polymerase chain reaction (PCR) using dsrA 575 and apsA genes. Microbial Ecology, 54, 439-451.

577 Brdjanovic, D., van Loosdrecht, M.C.M., Hooijmans, M.C., Alaerts, G.J., Heijnen, J.J., 578 1998. Minimal aerobic sludge retention time in biological phosphorus removal systems. 579 Biotechnology and Bioengineering, 60(3), 326-332.

581 Cassidy, J., Lubberding, H.J., Esposito, G., Keesman, K.J., Lens, P.N.L., 2015. Auto582 mated biological sulphate reduction: a review on mathematical models, monitoring and 583 bioprocess control. FEMS Microbiology Reviews, 39, 823-853.

585 Carvalheira, M., Oehmen, A., Carvalho, G., Reis, M.A.M., 2014. The impact of aeration 586 on the competition between polyphosphate accumulating organisms and glycogen ac587 cumulating organisms. Water Research, 66, 296-307.

588

589 Chandran, K., Smets, B.F., 2000. Single-step nitrification models erroneously describe 590 batch ammonia oxidation profiles when nitrite oxidation becomes rate limitng. Biotech591 nology and Bioengineering, 68(4), 396-406. 
593 Chanona, J., Ribes, J., Seco, A., Ferrer, J., 2006.Optimum design and operation of pri594 mary sludge fermentation schemes for volatile fatty acids production. Water Research, $59540,53-60$.

596

597 Chen, J.L., Ortiz, R., Steele, T.W.J., Stuckey, D.C., 2014. Toxicans inhibiting anaerobic 598 digestion: A review. Biotechnology Advances, 32, 1523-1534.

600 Ekama, G.A., Barnard, G.L., Gunthert, F.W., Krebs, P., McCorquodale, J.A., Parker, 601 D.S., Wahlberg, E.J., 1997. Secondary Settling Tanks: Theory, Modelling, Design and 602 Operation. International Association on Water Quality, London, UK.

603

604 Ge, H., Batstone, D.J., Keller, J., 2013. Operating aerobic wastewater treatment at very 605 short sludge ages enables treatment and energy recovery through anaerobic sludge di606 gestion. Water Research, 47, 6546-6557.

607

608 Ge, H., Batstone, D.J., Keller, J., 2015. Biological phosphorus removal from abattoir 609 wastewater at very short sludge ages mediated by novel PAO clade Comamonadaceae. 610 Water Research, 69, 173-182.

612 Geets, J., Borremans, B., Diels, L., Springael, D., Vangronsveld, J., van der Lelie, Van613 broekhove, K., 2006. DsrB gene-based DGGE for community and diversity surveys of 614 sulfate-reducing bacteria. Journal of Microbial Methods, 66, 194-205. 
Valverde-Pérez et al., 2016

615

616 González, J.M., Portillo, M.C., Belda-Ferre, P., Mira, A., 2012. Amplification by PCR

617 artificially reduces the proportion of the rare biosphere in microbial communities. Plos 618 One, 7(1), 1-11.

619

620 González-Martínez, A., Rodríguez-Sánchez, A., Lotti, T., García-Ruíz, M.J., Osorio, F., 621 González-López, J., van Loosdrecht, M.C.M., 2016. Comparison of bacterial communi622 ties of conventional and A-stage activated sludge systems. Scientific Reports, 6, 18786. 623

624 Guerrero, J., Guisasola, A., Baeza, J.A., 2011. The nature of the carbon rules the com625 petition between PAO and denitrifiers in systems for simultaneous biological nitrogen 626 and phosphorus removal. Water Research, 45, 4793-4802.

627

628 Gülay, A., Musovic, S., Alberchtsen, H.J., Al-Soud, W.A., Sørensen, S.J., Smets, B.F., 629 2016. Ecological patterns, diversity and core taxa of microbial communities in ground630 water-fed rapid gravity filters. The ISME journal, 1-14.

631

632 Guo, G., Wu, D., Hao, T., Mackey, H.R., Wei, L., Wang, H., Chen, G., 2016. Function633 al bacteria and process metabolism of the Denitrifying Sulfur conversion-associated 634 Enhanced Biological Phosphorus Removal (DS-EBPR) system: an investigation by op635 erating the system from deterioration to restoration. Water Research, 95, 289-299. 636 
637 Hao, T., Xiang, P., Mackey, H.R., Chi, K., Lu, H., Chui, H., van Loosdrecht, M.C.M.,

638 Chen, G.H., 2014. A review of biological sulfate conversions in wastewater treatment. 639 Water Research, 65, 1-21.

641 Hellinga, C., Schellen, A.A.J.C., Mulder, J.W., van Loosdrecht, M.C.M., Heijen, J.J., 642 1998. The SHARON process: an innovative method for nitrogen removal from ammo643 nium-rich waste water. Water Science and Technology, 37(9), 135-142.

644

645 Henze, M., Gujer, W., Mino, T., Matsuo, T., Wentzel, M.C., Marais, G.V.R., Van 646 Loosdrecht, M.C.M., 1999. Activated sludge model $\mathrm{n}^{\circ}$ 2d, ASM2d. Water Science and 647 Technology, 39, 165-182.

648

649 Hong, S., Bunge, J., Leslin, C., Jeon, S., Epstein, S.S., 2009. Polymerase chain reaction 650 primers miss half of rRNA microbial diversity. The ISME Journal, 3, 1365-1373.

652 Jasby, D., Xiao, Y., Schuler, A.J., 2014. Biomass density and filament length synergis653 tically affect activated sludge settling: systematic quantification and modeling. Water 654 Research, 48, 547-465.

655

656 Jeppsson, U., Alex, J, Batstone, D. J., Benedetti, L, Comas, J., Copp, J.B., Corominas, 657 L, Flores Alsina, X., Gernaey, K.V., Nopens, I., Pons, M.-N., Rodríguez-Roda, I., 
658 Rosen, C, Steyer, J.-P., Vanrolleghem, P.A., Volcke, E.I.P., Vrecko, D., 2013. Bench659 mark simulation models, quo vadis? Water Science and Technology, 68(1), 1-15. 660

661 Jensen, M.M., Petersen, J., Dalsgaard, T. Thamdrup, B., 2009. Pathways, rates and reg662 ulation of $\mathrm{N}_{2}$ production in the chemocline of an anoxic basin, Mariager Fjord, Den663 mark. Marine Chemistry, 113, 102-113.

664

665 Jimenez, J., Miller, M., Bott, C., Murthy, S., Clippeleir, H., Wett, B., 2015. High-rate 666 activated sludge system for carbon management - Evaluation of crucial process mecha667 nisms and design parameters. Water Research, 87, 476-482.

668

669 Kim, J., Lim, J., Lee, C., 2013. Quantitative real-time PCR approaches for microbial 670 community studies in wastewater treatment systems: applications and considerations. 671 Biotechnology Advances, 31, 1358-1373.

672

673 Kirchman, D.L., 2002.The ecology of Cytophaga-Flavobacteria in aquatic environ674 ments. FEMS Microbiology Ecology, 39, 91-100.

675

676 Kong, Y.H., Beer, M., Seviour, R.J., Lindrea, K.C., Rees, G., N., 2001. Structure and 677 functional analysis of the microbial community in an aerobic:anaerobic sequencing 678 batch reactor (SBR) with no phosphorus removal. Systematic Applied Microbiology, 679 24, 597-609. 
Valverde-Pérez et al., 2016

680

681 Liao, B.Q., Droppo, I.G., Leppard, G.C., Liss, S.N., 2006. Effect of solids retention 682 time on structure and characteristics of sludge flocs in sequencing batch reactors. Water 683 Research, 40, 2583-2591.

684

685 López-Vázquez, C.M., Oehmen, A., Hooijmans, C.M., Brdjanovic, D., Gijzen, H.J., 686 Yuan, Z., van Loosdrechtm, M.C.M., 2009. Modeling the PAO-GAO competition: ef687 fects of carbon source, $\mathrm{pH}$ and temperature. Water Research, 43, 450-462.

688

689 Lv, X.M., Shao, M.F., Li, J., Li, C.L., 2015. Metagenomic analysis of the sludge micro690 bial community in lab-scale denitrifying phosphorus removal reactor. Applied Bio691 chemistry and Biotechnology, 175, 3258-3270.

692

693 Mamais, D., Jenkins, D., 1992. The effect of MCRT and temperature on enhanced bio694 logical phosphorus removal. Water Science and Technology, 26(5-6), 955-965.

695

696 Martins, A.M.P., Pagilla, K., Heijnen, J.J., van Loosdrecht, M.C.M., 2003. Filamentous 697 bulking sludge - a critical review. Water Research, 38(4), 793-817.

698

699 Maurer, M., Gujer, W., 1995. Monitoring of microbial phosphorus release in batch ex700 periments using electric conductivity. Water Research, 29(11), 2613-2617. 701 
702 McCartney, D.M., Oleszkiewicz, J.A., 1991. Sulfide inhibition of anaerobic degradation 703 of lactate and acetate. Water Research, 25(2), 203-209.

705 Meerburg, F.A., Boon, N., Van Winckel, T., Vercamer, J.A.R., Nopens, I., Vlaemink, 706 S.E., 2015. Toward energy-neutral wastewater treatment: a high-rate contact stabiliza707 tion process to maximally recover sewage organics. Bioresource Technology, 179, 373708381.

710 Meerburg, F.A., Vlaeminck, S.E., Roume, H., Seuntjens, D., Pieper, D.H., Jauregui, R., 711 Vilchez-Vargas, R., Boon, N., 2016. High-rate activated sludge communities have a 712 distinctly different structure compared to low-rate sludge communities, and are less 713 sensitive towards environmental and operational variables. Water Research, 100, 137714145.

716 Meinhold, J., Arnold, E., Isaacs, S., 1999. Effect of nitritate on anoxic phosphate uptake 717 in biological phosphorus removal activated sludge. Water Research, 33(8), 1871-1883. 718

719 Mielczarek, A.T, Kragelund, C., Eriksen, P.S., Nielsen, P.H., 2012. Population dynam720 ics of filamentous bacteria in Danish wastewater treatment plants with nutrient removal. 721 Water Research, 46, 3781-3795. 
Valverde-Pérez et al., 2016

723 Mielczarek, A.T., Nguyen, H.T.T., Nielsen, J.L., Nielsen, P.H., 2013. Population dy724 namics of bacteria involved in enhanced biological phosphorus removal in Danish 725 wastewater treatment plants. Water Research, 47, 1529-1544.

727 Mino, T., van Loosdrecht, M.C.M., Heijen, J.J., 1998. Microbiology and biochemistry 728 of the enhanced biological phosphate removal process. Water Research, 32(11), 31937293207.

730

731 Miyazato, N., Yamamoto-Ikemoto, R., Takamatsu, S., 2006. Microbial community 732 change of sulfate reduction and sulfur oxidation in the activated sludge cultivated with 733 acetate and peptone. Water Science and Technology, 54(8), 111-119.

734

735 Nielsen, P.H., Daims, H., Lemmer, H., 2009. FISH Handbook for Biological 736 Wastewater Treatment. Identification and Quantification of Microorganisms in Activat737 ed Sludge and Biofilms by FISH. IWA Publishing, London, UK.

738

739 Nielsen, P.H., Kragelund, C., Seviour, R.J., Nielsen, J.L., 2009b. Identity and ecophysi740 ology of filamentous bacteria in activated sludge. FEMS Microbiology Reviews, 33, $741969-998$.

742

743 Nielsen, P.H., Mielczarek, A.T., Kragelund, C., Nielsen, J.L., Saunders, A.M., Kong, 744 Y., Hansen, A.A., Vollertsen, J., 2010. A conceptual ecosystem model of microbial 
Valverde-Pérez et al., 2016

745 communities in enhanced biological phosphorus removal plants. Water Research, 44, $746 \quad 5070-5088$.

748 Nielsen, P.H., Saunders, A.M., Hansen, A.A., Larsen, P., Nielsen, J.L., 2012. Microbial 749 communities involved in enhanced biological phosphorus removal from wastewater - a 750 model system in environmental biotechnology. Current Opinion in Biotechnology, 23, $751 \quad 452-459$.

752

753 Noutsopoulos, C., Mamais, D., Andreakis, A., 2006. Effects of solids retention time on 754 Microthrix parvicella growth. Water SA, 32(3), 315-321.

755

756 Oehmen, A., Lemos, P.C., Carvalho, G., Yuan, Z., Keller, J, Blackhall, L.L., Reis, 757 M.A.M., 2007. Advances in enhanced biological phosphorus removal: from micro to 758 macro scale. Water Research, 41, 2271-2300.

759

760 Oehmen, A., Carvalho, G., Lopez-Vazquez, C.M., van Loosdrecht, M.C.M., Reis, 761 M.A.M., 2010. Incorporating microbial ecology into the metabolic modelling of poly762 phosphate accumulating organisms and glycogen accumulating organisms. Water Re763 search, 44(17), 4992-5004.

764

765 Pellicer-Nàcher, C., Frank, S., Gülay, A., Ruscadella, M., Terada, A., Al-Soud, W.A., 766 Hansen, M.A., Sørensen, S.J., Smets, B.F., 2013. Sequentially aerated membrane bio- 
Valverde-Pérez et al., 2016

767 film reactors for autotrophic nitrogen removal: microbial community composition and 768 dynamics. Microbial Biotechnology, 7, 32-43.

769

770 Pester, M., Bittner, N., Deevong, P., Wagner, M., Loy, A., 2010. A “rare biosphere” 771 microorganism contributes to sulfate reduction in a peatland. The ISME Journal, 4(12), 772 1-12.

773

774 Pfennig, N., Biebl, H., 1976. Desulfuromonas acetoxidans gen. nov. and sp. nov., a new 775 anaerobic, sulfur-reducing, acetate-oxidizing bacterium. Archives of Microbiology, 110, $776 \quad 3-12$

777

778 Pijuan, M., Ye, L., Yuan, Z., 2010. Free nitrous acid inhibition on the aerobic metabo779 lism of poly-phosphate accumulating organisms. Water Research, 44, 6063-6072.

780

781 Plugge, C.M., Zhang, W., Scholten, J.C.M., Stams, A.J.M., 2011. Metabolic flexibility 782 of sulfate-reducing bacteria. Frontiers in Microbiology, 2, 1-8.

783

784 Regmi, P., Miller, M.W., Holgate, B., Bunce, R., Park, H., Chandran, K., Wett, B., 785 Murthy, S., Bott, C.B., 2014. Control of aeration, aerobic SRT and COD input for mai786 instream nitritiation/denitritation. Water Research, 57, 162-171. 
788 Reis, M.A.M., Almeida, J.S., Lemos, P.C., Carrondo, M.J.T., 1992. Effect of hydrogen 789 sulfide on growth of sulfate reducing bacteria. Biotechnology and Bioengineering, 40, $790 \quad 593-600$.

792 Saa, S., Welles, L., López-Vázquez, C., van Loosdrecht, M.C.M., 2013. Sulfide effects 793 on the anaerobic kinetics of phosphorus accumulating organisms. Proceedings of the 794 World Congress on Anaerobic Digestion, Santiago de Compostela, Spain.

796 Sadaie, T., Sadaie, A., Takada, M., Hamano, K., Ohnishi, J., Ohta, N., Matsumoto, K., 797 Sadaie, Y., 2007. Reducing sludge production and domination of Comamonadaceae by 798 reducing the oxygen supply in the wastewater treatment procedure of a food-processing 799 factory. Biosciences, Biotechnology and Biochemistry, 71(3), 791-799. 800

801 Saunders, A.M., Albertsen, M., Vollertsen, J., Nielsen, P.H., 2016. The activated sludge 802 ecosystem contains a core community of abundant organisms. The ISME Journal, 10, 803 11-20.

804

805 Schneider, D.W., 2014. Who invented activated sludge? Environmental Engineering 806 and Scientist, 50(1), 8-11. 
808 Schuler, A.J., Jang, H., 2007. Causes of variable biomass density and its effects on set809 tleability in full-scale biological wastewater treatment systems. Environmental Science 810 and Technology, 41, 1675-1681.

812 Shilton, A. N., Powell, N., Guieysse, B., 2012. Plant based phosphorus recovery from 813 wastewater via algae and macrophytes. Current Opinion in Biotechnology, 23, 884-889.

815 Shoener, B.D., Bradley, I.M., Cusick, R.D., Guest, J.S., 2014. Energy positive domestic 816 wastewater treatment: the roles of anaerobic and phototrophic technologies. Environ817 mental Science Process and Impacts, 16, 1204-1222.

819 Sheik, A.R., Muller, E.E.L., Wilmes, P., 2014. A hundred years of activated sludge: 820 time for a rethink. Frontiers in Microbiology, 47(5), 1-7.

822 Sin, G., Villez, K., Vanrolleghem, P.A., 2006. Application of a model-based optimisa823 tion methodology for nutrient removing SBRs leads to falsification of the model. Water 824 Science and Technology, 53(4-5), 95-103.

826 Sun, H., Spring, S., Lapidus, A., Davenport, K., Del Rio, T.G., Tice, H., Nolan, M., 827 Copeland, A., Cheng, J.F., Lucas, S., Tapia, R., Goodwin, L., Pitluck, S., Ivanova, N., 828 Pagani, I., Mavromatis, K., Ovchinnikova, G., Pati, A., Chen, A., Palaniappan, K., 829 Hauser, L., Chang, Y.J., Jeffries, C.D., Detter, J.C., Han, C., Rohde, M., Brambilla, E., 
830 Göker, M., Woyke, T., Bristow, J., Eisen, J.A., Markowitz, V., Hugenholtz, P., 831 Kyrpides, N.C., Klenl, H.P., Land, M., 2010. Complete genome sequence of Desulfar832 culus baarsii type strain $\left(2 \mathrm{st} 14^{\mathrm{T}}\right)$. Standards in Genomic Sciences, 3, 276-284.

834 Tandoi, V., Jenkins, D., Wanner, J. 2006. Activated sludge separation problems: theory, 835 control measurements, practical experiences., London, UK.

Terada, A., Lackner, S., Kristensen, K., Smets, B.F., 2010. Inoculum effects on community composition and nitritation performance of autotrophic nitrifying biofilm reators 839 with counter-diffusion geometry. Environmental Microbiology, 12(10), 2858-2872.

841 Vaiopoulou, E., Melidis, P., Aivasidis, A., 2007. Growth of filamentous bacteria in an 842 enhanced biological phosphorus removal system. Desalination, 213, 288-296.

844 Valverde-Pérez, B., Ramin, E., Smets, B.F., Plósz, B.Gy., 2015. EBP2R - An innova845 tive enhanced biological nutrient recovery activated sludge system to produce growth 846 medium for green microalgae cultivation. Water Research, 68, 821-830.

848 Valverde-Pérez, B., Wágner, D.S., Cecchin, F., Jensen, C.J., Smets, B.F., Plósz, B. Gy., 849 2015b. Impact of operational conditions and process configuration on process perfor850 mance and microbial community in short solid retention time EBPR systems. $1^{\text {st }}$ IWA 851 Resource Recovery Conference, Ghent, Belgium. 
Valverde-Pérez et al., 2016

852

853 Valverde-Pérez, B., 2015. Wastewater resource recovery via the enhanced biological 854 phosphorus removal and recovery (EBP2R) process coupled with green microalgae cul855 tivation. PhD thesis, Technical University of Denmark, Kgs. Lyngby, Denmark.

856

857 Valverde-Pérez, B., Fuentes-Martínez, J.M., Flores-Alsina, X., Gernaey, K.V., Huusom, 858 J.K., Plósz, B.Gy., 2016. Control structure design for resource recovery using the en859 hanced biological phosphorus removal and recovery (EBP2R) activated sludge process. 860 Chemical Engineering Journal, 296, 447-457.

861

862 Van den Brand, T.P.H., Roest, K., Chen, G.H., Brdjanovic, D., van Loosdrecht, 863 M.C.M., 2015. Occurrence and activity of sulphate reducing bacteria in aerobic activat864 ed sludge systems. World Journal on Microbiology and Biotechnology, 31, 507-516. 865

866 Verstraete, W., Van de Caveye, P., Diamantis, V., 2009. Maximum use of resources 867 present in domestic “used water”. Bioresource Technology, 100, 5537-5545. 868

869 Wágner, D.S., Ramin, E., Szabo, P., Dechesne, A., Plósz, B.Gy., 2015. Microthrix par870 vicella abundance associates with activated sludge settling velocity and rheology 871 Quantifying and modelling filamentous bulking. Water Research, 78, 121-132. 872 
873 Wang, Y., Zhou, S., Ye, L., Wang, H., Stephenson, T., Jiang, X., 2014. Nitrite survival 874 and nitrous oxide production of denitrifying phosphorus removal sludges in long-term 875 nitrite/nitrate-fed sequencing batch reactors. Water Research, 67, 33-45.

876

877 Whang, L.M., Park, J.K., 2006. Competition between polyphosphate and glycogen ac878 cumulating organisms in enhanced biological phosphorus removal systems: effect of 879 temperature and sludge age. Water Environment Research, 78, 4-11.

880

881 Wu, D., Ekama, G.A., Wang, H.G., Wei, L., Lu, H., Chui, H.K., Liu, W.T., Brdjanovic, 882 D., van Loosdrecht, M.C.M., Chen, G.H., 2014. Simultaneous nitrogen and phosphorus 883 removal in the sulfur cycle-associated Enhanced Biological Phosphorus Removal 884 (EBPR) process. Water Research, 49, 251-264.

885

886 Yamamoto-Ikemoto, R., Komori, T., Matsui, S., 1991. Filamentous bulking and hinder887 ance of phosphate removal due to sulfate reduction in activated sludge. Water Science 888 and Technology, 23, 927-935.

889

890 Yamamoto-Ikemoto, R., Matsui, S., Komori, T., 1994. Ecological interactions among 891 denitrification, poly-p accumulation, sulfate reduction, and filamentous sulfur bacteria 892 in activated sludge. Water Science and Technology, 30(11), 201-210. 893 
894 Yamamoto-Ikemoto, R., Matsui, S., Komori, T., Bosque-Hamilton, E.J., 1996. Symbio895 sis and competition among sulfate reduction, filamentous sulfur, denitrification and 896 poly-P accumulation bacteria in the anaerobic-oxic activated sludge of a municipal 897 plant. Water Science and Technology, 34(5-6), 119-128.

898

899 Yuan, Z., Pratt, S., Batstone, D.J., 2012. Phosphorus recovery from wastewater through 900 microbial processes. Current opinion in biotechnology, 23, 878-883.

901

902 Zhou, J., He, Q., Hemme, C.L., Mukhpadhyay, A., Hillesland, K., Zhou, A., He, Z., 903 Van Nostrand, J.D., Hazen, T.C., Stahl, D.A., Wall, J.D., Arkin, A.P., 2011. How sul904 phate-reducing microorganisms cope with stress: lessons from systems biology. Nature, 9059 9, 452-466.

906 
Valverde-Pérez et al., 2016

907
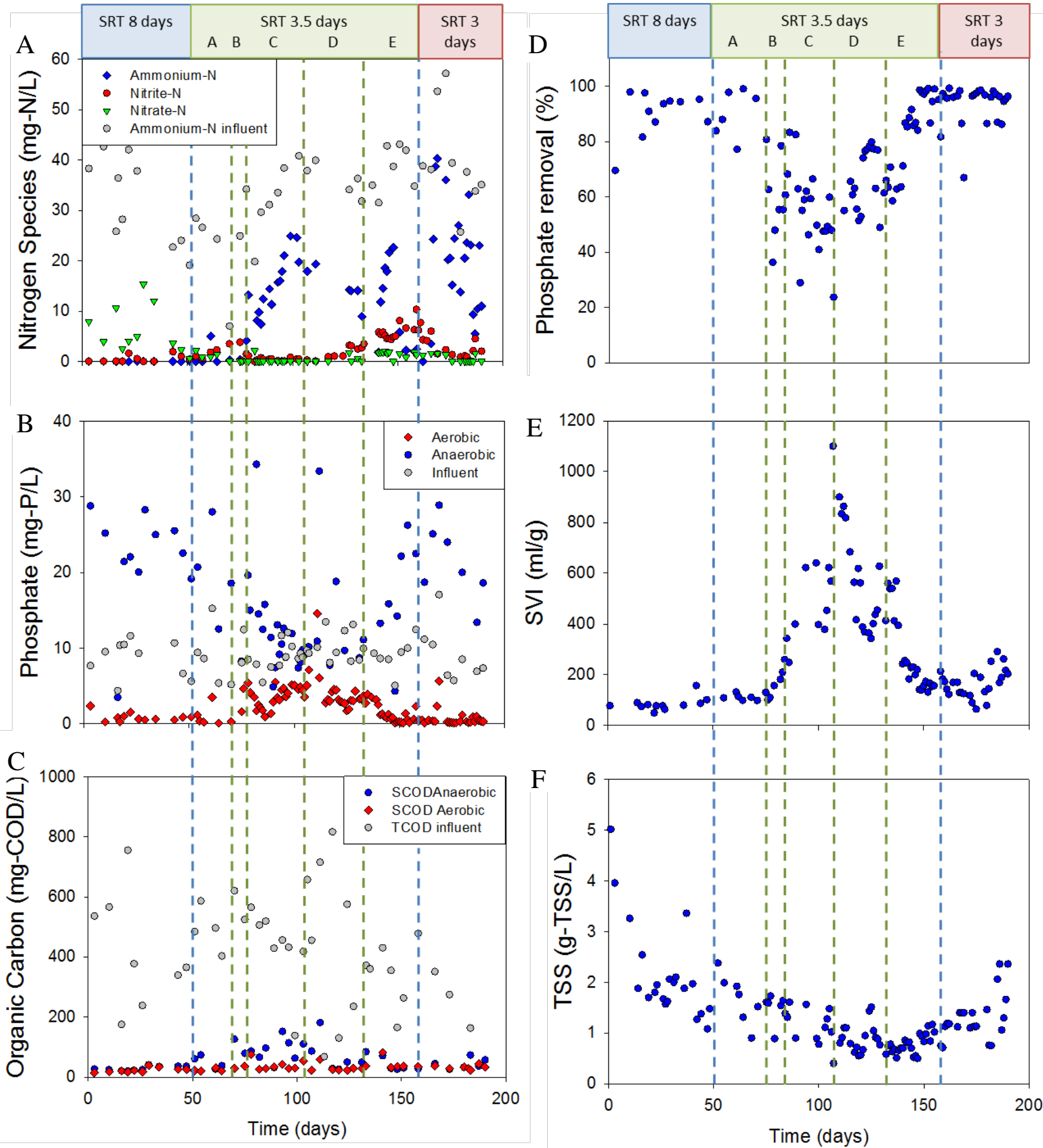

909 Figure 1: Reactor performance through 190 days a) Ammonia, nitrite and nitrate at the end of the aer-

910 obic phase and ammonia in the influent; b) phosphate at the end of the aerobic and anaerobic phases 
911 and influent; c) soluble COD at the end of the anaerobic and aerobic phases and total COD in the influ912 ent; d) phosphate removal; e) sludge volume index; f) total suspended solids. Phase A: from day 50 to 913 day 78 - anaerobic SRT=1.2 d and aerobic SRT=1.75 d; phase B: from day 78 to 83 - anaerobic 914 SRT=1.2 d and aerobic SRT=1.45 d; phase C: from day 83 to 109 - anaerobic SRT=1.2 d and aerobic 915 SRT=1.75 d; phase D: from day 109 to day 132 - anaerobic SRT=0.88 d and aerobic SRT=1.75 d; 916 phase E: from day 132 to day 156 - anaerobic SRT=0.68 d and aerobic SRT=1.75 d.

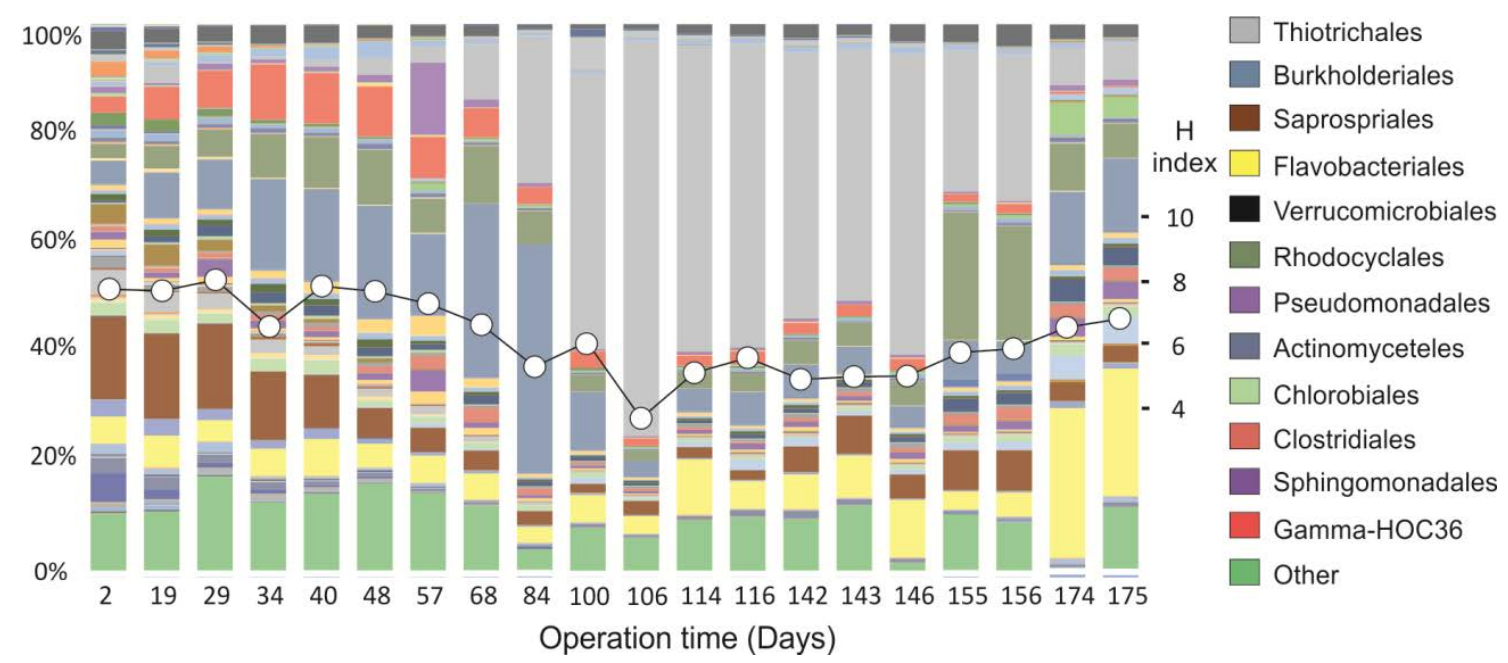

920 Figure 2: Order-level taxonomic classification of 16S rRNA amplicons at selected days of the reactor 921 operation. Taxa abundance is expressed in percentage (left axis). Alpha-diversity at the order level 922 measured as Shannon index (white dots, right axis). 


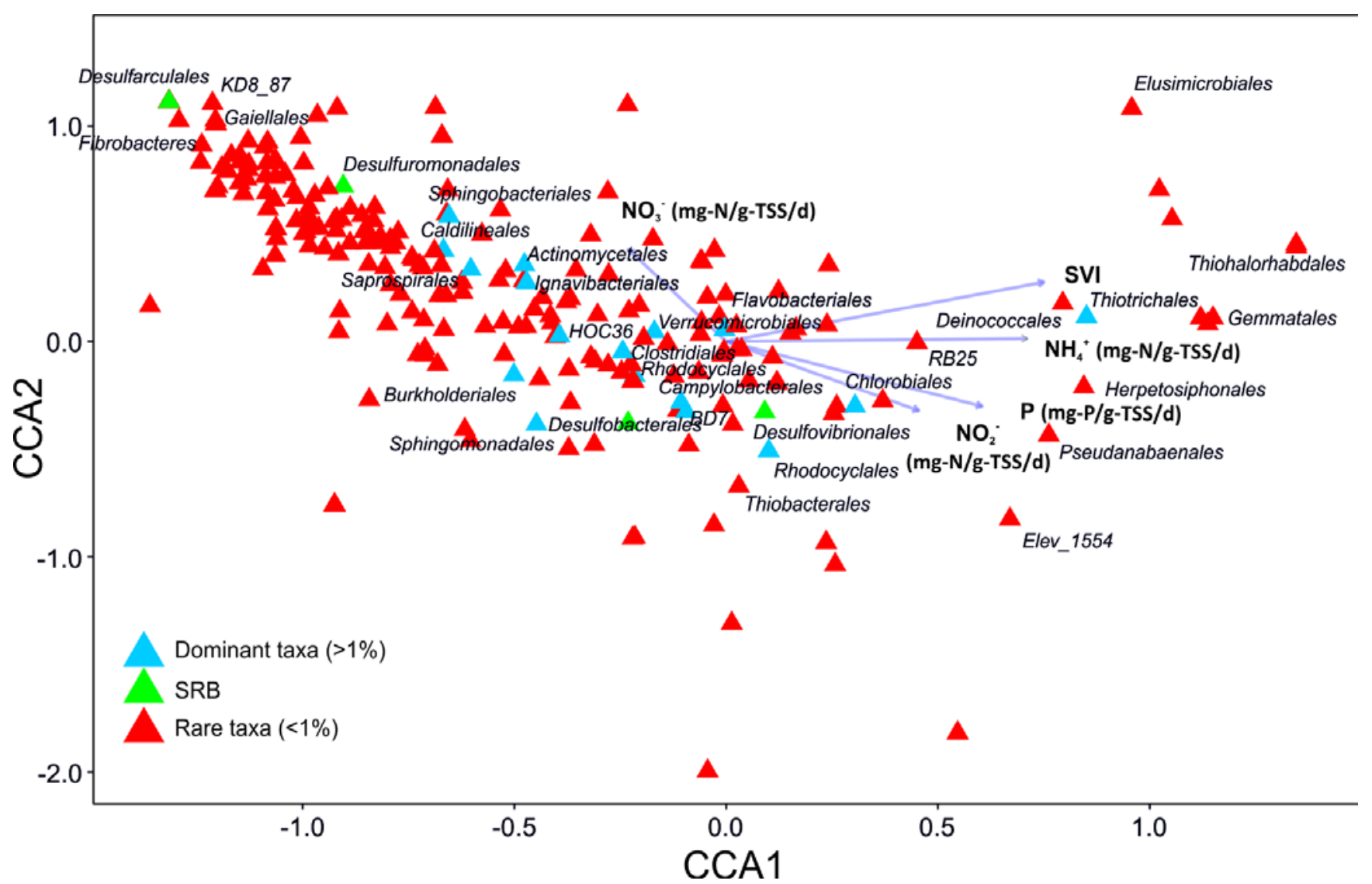

925 Figure 3: Canonical correspondence analysis (CCA) of order-level taxa within samples taken at time 926 points during reactor operation constrained by five environmental variables: SVI ( $\left.\mathrm{mL} \mathrm{g}^{-1}\right)$, ammonium 927 removal (mg-N L-1 g-VSS${ }^{-1}$ ), nitrite accumulation (mg-N L ${ }^{-1}$ g-VSS ${ }^{-1}$ ), nitrate accumulation (mg- $\mathrm{N} \mathrm{L}^{-1}$

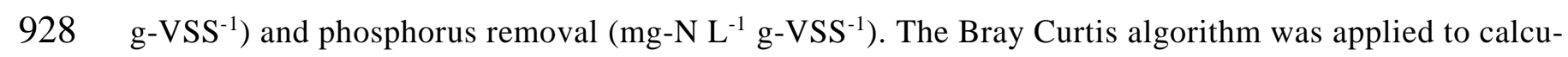
929 late dissimilarity values. 


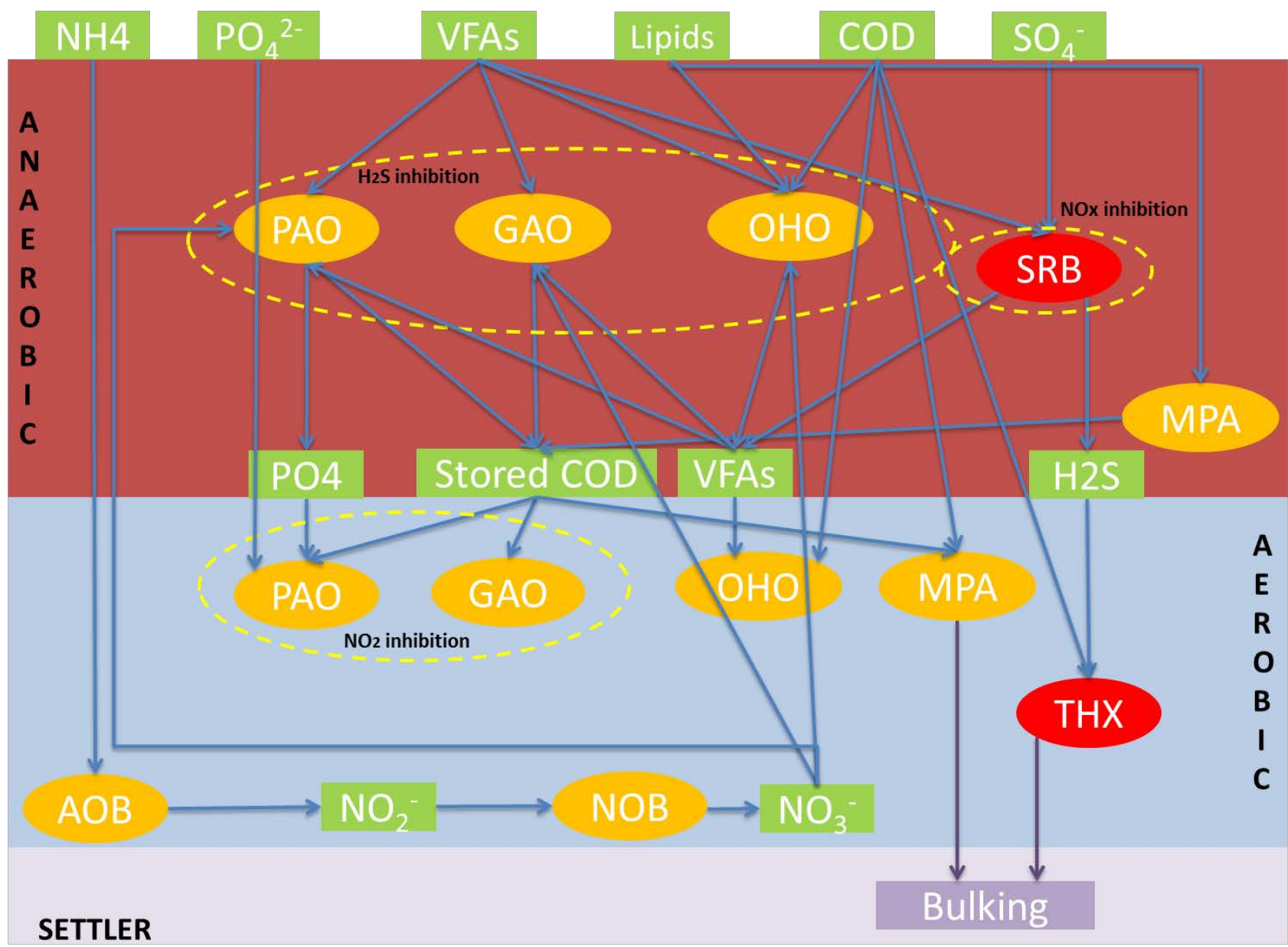

932 Figure 4: Ecological model proposed for the low-SRT EBPR system. Circled in yellow 933 those microbial groups inhibited by chemicals (e.g. nitrite). Colored in red those micro934 bial niches playing an important role in short-SRT EBPR systems but not acknowledged 935 in previous studies. Blue arrows represent the substrate and products flows. PAO: poly936 phosphate accumulating organisms; GAO: glycogen accumulating organisms; OHO: 937 ordinary heterotrophic organisms; SRB: sulphate reducing bacteria; MPA: Microthrix 938 parvicella; THX: Thiothrix; AOB: ammonia oxidizing bacteria; NOB: nitrite oxidizing 939 bacteria. 
Valverde-Pérez et al., 2016

941 Table 1: Operational conditions during the start-up and operation of the short-SRT 942 EBPR:

\begin{tabular}{|c|c|c|c|c|}
\hline $\begin{array}{l}\text { Period } \\
\text { (day) }\end{array}$ & $\begin{array}{c}\text { Global SRT } \\
\text { (day) }\end{array}$ & $\begin{array}{c}\text { Anaerobic SRT } \\
\text { (day) }\end{array}$ & $\begin{array}{c}\text { Aerobic SRT } \\
\text { (day) }\end{array}$ & $\begin{array}{c}\text { Oxygen level (mg } \\
\left.\mathrm{L}^{-1}\right)\end{array}$ \\
\hline $1-50$ & 8 & 2.67 & 4 & \multirow{3}{*}{$2-3$} \\
\hline $51-78$ & \multirow{5}{*}{3.5} & \multirow{3}{*}{1.2} & 1.75 & \\
\hline $79-83$ & & & 1.45 & \\
\hline 84-109 & & & \multirow[t]{3}{*}{1.75} & $\begin{array}{c}2-3 \text { (first week } \\
0.5-2 \text { ) }\end{array}$ \\
\hline $110-132$ & & 0.88 & & \multirow{2}{*}{$>4.5$} \\
\hline 133-149 & & 0.68 & & \\
\hline $150-190$ & 3 & 0.58 & 1.5 & $2-3$ \\
\hline
\end{tabular}

943

944 
945 Supplementary information

946

947 Short-sludge age EBPR process - microbial and biochem948 ical process characterisation during reactor start-up and 949 operation

950 Borja Valverde-Pérez*, Dorottya S. Wágner, Bálint Lóránt, Arda Gülay, Barth F. 951 Smets, Benedek Gy. Plósz*

952 Department of Environmental Engineering (DTU Environment), Technical University of Denmark, Miljøvej, Building 115, DK-

953 2800, Kgs. Lyngby, Denmark. E-mails: bvape@env.dtu.dk; beep@env.dtu.dk

$954 *$ Corresponding authors

955

956

957 


\section{Quantitative polymerase chain reaction (qPCR)}

Reactor biomass was collected as $2 \mathrm{~mL}$ samples, centrifuged at 13000xg, supernatants were removed and pellets were stored at $-20{ }^{\circ} \mathrm{C}$ until further analysis. A $0.5 \mathrm{~g}$ subsample of reactor samples was subject to genomic DNA extraction using the MP FastDNA $^{\text {TM }}$ SPIN Kit (MP Biomedicals LLC., Solon, USA) per manufacturer's instructions. The concentration and purity of extracted DNA were checked by spectrophotometry (NanoDrop Technologies, Wilmington, DE, USA). Extracted DNA was stored at -20 ${ }^{0} \mathrm{C}$ in Tris-EDTA buffer until further processing. Quantitative PCR (qPCR) was carried out on all the extracted DNA samples to determine the abundance of ammonia oxidizing bacteria (AOB) and nitrite oxidizing bacteria (NOB, both Nitrobacter and Nitrospira) as suggested by Terada et al., (2010), Thiothrix (protocol adapted from Vervaeren et al., 2005), Microthrix parvicella (protocol adapted from Kaetzke et al., 2005; Kumari et al.,

2009; and Vanysacker et al., 2014) and sulphate reducing bacteria (SRB, protocol adapted from Wagner et al, 1998; and Geets et al., 2006). Primers used in this work to target the 16S rRNA genes and the functional gene dsrB for SRB are included in Table S1, together with the PCR protocols. For quantification, 1 copy of 16S rRNA gene for AOB and NOB, 1.33 copies of 16S rRNA gene for Microthrix parvicella, and 4.1 copies of 16S rRNA gene for total bacteria (Stoddard et al., 2014), 2 copies of 16S rRNA gene for Thiothrix (Lapidus et al., 2011) and 1 copy of the functional gene dsrB for SRB (Karkhoff-Schweizer et al., 1995) were considered. 
Valverde-Pérez et al., 2016

Table S1: Primer sets for qPCR

\begin{tabular}{|c|c|c|c|c|}
\hline Organism & Gene & Primers & Sequence $\left(5^{\prime} \rightarrow 3^{\prime}\right)$ & Reference \\
\hline \multirow{2}{*}{ Total Bacteria } & \multirow{2}{*}{$\begin{array}{l}\text { 16S- } \\
\text { rRNA }\end{array}$} & $1055 f$ & ATGGCTGTCGTCAGCT & Ferris et al. 1996 \\
\hline & & $1392 \mathrm{r}$ & ACGGGCGGTGTGTAC & Lane 1991 \\
\hline \multirow{3}{*}{$\begin{array}{l}\beta \text {-proteobacterial } \\
\text { AOB }\end{array}$} & \multirow{3}{*}{$\begin{array}{l}\text { 16S- } \\
\text { rRNA }\end{array}$} & CTO189fA/B & GGAGRAAAGCAGGGGATCG & \multirow{3}{*}{$\begin{array}{l}\text { Kowalchuk et al. } 1997 \\
\text { Hermansson and Lindgren } 2001\end{array}$} \\
\hline & & СТО 189fC & GGAGGAAAGTAGGGGATCG & \\
\hline & & RT1r & CGTCCTCTCAGACCARCTACTG & \\
\hline \multirow{2}{*}{$\begin{array}{l}\text { Nitrospira genus } \\
\text { NOB }\end{array}$} & \multirow{2}{*}{$\begin{array}{l}\text { 16S- } \\
\text { rRNA }\end{array}$} & Nspra-675f & GCGGTGAAATGCGTAGAKATCG & \multirow{2}{*}{ Graham et al. 2007} \\
\hline & & Nspra-746r & TTTTTTGAGATTTGCTAG & \\
\hline \multirow{2}{*}{$\begin{array}{l}\text { Nitrobacter genus } \\
\text { NOB }\end{array}$} & \multirow{2}{*}{$\begin{array}{l}\text { 16S- } \\
\text { rRNA }\end{array}$} & FGPS872f & CTAAAACTCAAAGGAATTGA & \multirow[b]{2}{*}{ Degrange and Bardin, 1995} \\
\hline & & FGPS1269r & TTTTTTGAGATTTGCTAG & \\
\hline \multirow{4}{*}{$\begin{array}{l}\text { Sulfate reducing } \\
\text { bacteria }\end{array}$} & \multirow[t]{2}{*}{ dsrA } & RH1-dsr-F & GCCGTTACTGTGACCAGCC & \multirow{2}{*}{ Ben-Dov et al. 2007} \\
\hline & & RH3-dsr-R & GGTGGAGCCGTGCATGTT & \\
\hline & \multirow{2}{*}{ dsrB } & DSRp2060F & CAACATCGTYCAYACCCAGGG & Geets et al. 2006 \\
\hline & & DSR4R & GTGTAGCAGTTACCGCA & Wagner et al. 1998 \\
\hline \multirow{2}{*}{ Thiothrix } & \multirow{2}{*}{$\begin{array}{l}\text { 16S- } \\
\text { rRNA }\end{array}$} & $21 \mathrm{Nf}$ & CGTAGGCGGCTCTTTAAGTCRGAT & \multirow{2}{*}{ Vervaeren et al. 2005} \\
\hline & & $21 \mathrm{Nr}$ & CCGACGGCTAGTTGACATCGTTTA & \\
\hline \multirow{3}{*}{$\begin{array}{l}\text { Microthrix par- } \\
\text { vicella }\end{array}$} & \multirow{3}{*}{$\begin{array}{l}\text { 16S- } \\
\text { rRNA }\end{array}$} & $\begin{array}{l}\text { S-S-M.par-0828- } \\
\text { S-21f }\end{array}$ & GGTGTGGGGAGAACTCAACTC & \multirow{3}{*}{$\begin{array}{l}\text { Kaetzke, A. et al. } 2005 \\
\text { Kumari, A. et al. } 2009 \\
\text { Vanysacker, L. et al. } 2014\end{array}$} \\
\hline & & & & \\
\hline & & $\begin{array}{l}\text { S-S-M1.par-1018- } \\
\text { A-17r }\end{array}$ & GACCCCGAAGGACACCG & \\
\hline
\end{tabular}

III - 51 
Table S2: Real time quantitative PCR conditions for "Most Bacteria”

\begin{tabular}{l|c|c}
\hline & Temperature $\left[{ }^{\circ} \mathrm{C}\right]$ & Time $[\mathbf{m i n}: \mathbf{s e c}]$ \\
\hline 1. Pre-heating & $\mathbf{9 4}$ & $\mathbf{5 : 0 0}$ \\
2. Denaturation & $\mathbf{9 4}$ & $\mathbf{0 : 3 0}$ \\
3. Annealing & 55 & $\mathbf{0 : 3 0}$ \\
4. Elongation & 72 & $\mathbf{1 : 0 0}$ \\
5. Plate read & & $\mathbf{0 : 0 1}$ \\
& & $\mathbf{0 : 0 1}$ \\
6. Melting curve & $\mathbf{7 0 - 9 5}$ & $\infty$ \\
7. Cooling & $\mathbf{2 0}$ & \\
\hline
\end{tabular}

Back to 2. Repeat 39 times

Gradient $0.2^{\circ} \mathrm{C} / \mathrm{s}$

Table S3: Real time quantitative PCR conditions for AOB

\begin{tabular}{l|c|c}
\hline & Temperature $\left[{ }^{\circ} \mathrm{C}\right]$ & Time [min:sec] \\
\hline 1. Pre-heating & $\mathbf{9 4}$ & $\mathbf{5 : 0 0}$ \\
2. Denaturation & $\mathbf{9 4}$ & $\mathbf{0 : 3 0}$ \\
3. Annealing & $\mathbf{6 0}$ & $\mathbf{0 : 3 0}$ \\
4. Elongation & $\mathbf{7 2}$ & $\mathbf{1 : 0 0}$ \\
5. Plate read & & $\mathbf{0 : 0 1}$ \\
6. Melting curve & $\mathbf{7 0 - 9 5}$ & $\mathbf{0 : 0 1}$ \\
7. Cooling & $\mathbf{2 0}$ & $\infty$
\end{tabular}

Back to 2. Repeat 39 times

Gradient $0.2^{\circ} \mathrm{C} / \mathrm{s}$

Table S4: Real time quantitative PCR conditions for Nitrospira sp.

\begin{tabular}{l|c|c}
\hline & Temperature $\left[{ }^{\circ} \mathrm{C}\right]$ & Time [min:sec] \\
\hline 1. Pre-heating & $\mathbf{9 4}$ & $5: 00$ \\
2. Denaturation & $\mathbf{9 4}$ & $\mathbf{0 : 3 0}$ \\
3. Annealing & $\mathbf{6 4}$ & $\mathbf{0 : 3 0}$ \\
4. Elongation & 72 & $\mathbf{1 : 0 0}$ \\
5. Plate read & & $\mathbf{0 : 0 1}$ \\
6. Melting curve & $\mathbf{7 0 - 9 5}$ & $\mathbf{0 : 0 1}$ \\
7. Cooling & $\mathbf{2 0}$ & $\infty$ \\
\hline
\end{tabular}

Back to 2. Repeat 39 times

Gradient $0.2^{\circ} \mathrm{C} / \mathrm{s}$ 
Table S5: Real time quantitative PCR conditions for Nitrobacter

\begin{tabular}{l|c|c}
\hline & Temperature $\left[{ }^{\circ} \mathbf{C}\right]$ & Time [min:sec] \\
\hline 1. Pre-heating & $\mathbf{9 5}$ & $\mathbf{5 : 0 0}$ \\
2. Denaturation & $\mathbf{9 4}$ & $\mathbf{0 : 4 5}$ \\
3. Annealing & $\mathbf{5 0}$ & $\mathbf{1 : 0 0}$ \\
4. Elongation & $\mathbf{7 2}$ & $\mathbf{1 : 0 0}$ \\
5. Plate read & & \\
6. Melting curve & $\mathbf{7 0 - 9 5}$ & $\mathbf{0 : 0 1}$ \\
7. Cooling & $\mathbf{2 0}$ & $\infty$ \\
\hline
\end{tabular}

Back to 2. Repeat 39 times

Gradient $0.2^{\circ} \mathrm{C} / \mathrm{s}$

Table S6: Real time quantitative PCR conditions for Sulphate reducing bacteria dsrA gene

\begin{tabular}{l|c|c}
\hline & Temperature $\left[{ }^{\circ} \mathrm{C}\right]$ & Time $[\mathbf{m i n}: \mathbf{s e c}]$ \\
\hline 1. Pre-heating & $\mathbf{9 5}$ & $\mathbf{5 : 0 0}$ \\
2. Denaturation & 95 & $\mathbf{0 : 1 5}$ \\
3. Annealing & $\mathbf{6 0}$ & $\mathbf{1 : 0 0}$ \\
4. Elongation & 72 & $\mathbf{1 : 0 0}$ \\
5. Plate read & & \\
6. Melting curve & $\mathbf{7 0 - 9 5}$ & $\mathbf{0 : 0 1}$ \\
7. Cooling & $\mathbf{2 0}$ & $\infty$
\end{tabular}

Back to 2. Repeat 40 times $0,2{ }^{\circ} \mathrm{C} / \mathrm{s}$

Table S7: Real time quantitative PCR conditions for Sulphate reducing bacteria dsrB gene

\begin{tabular}{l|c|c}
\hline & Temperature $\left[{ }^{\circ} \mathrm{C}\right]$ & Time $[\mathbf{m i n}: \mathbf{s e c}]$ \\
\hline 1. Pre-heating & $\mathbf{9 4}$ & $\mathbf{5 : 0 0}$ \\
2. Denaturation & $\mathbf{9 4}$ & $\mathbf{1 : 0 0}$ \\
3. Annealing & $\mathbf{5 6 , 9}$ & $\mathbf{1 : 0 0}$ \\
4. Elongation & $\mathbf{7 2}$ & $\mathbf{1 : 0 0}$ \\
5. Plate read & & \\
6. Melting curve & $\mathbf{7 0 - 9 5}$ & $\mathbf{0 : 0 1}$ \\
7. Cooling & $\mathbf{2 0}$ & $\infty$
\end{tabular}

Back to 2. Repeat 39 times

$0,2^{\circ} \mathrm{C} / \mathrm{s}$ 
Table S8: Real time quantitative PCR conditions for Thiothrix

\begin{tabular}{l|c|c}
\hline & Temperature $\left[{ }^{\circ} \mathrm{C}\right]$ & Time [min:sec] \\
\hline 1. Pre-heating & $\mathbf{9 5}$ & $\mathbf{5 : 0 0}$ \\
2. Denaturation & $\mathbf{9 5}$ & $\mathbf{0 : 4 5}$ \\
3. Annealing & $\mathbf{6 0}$ & $\mathbf{1 : 0 0}$ \\
4. Elongation & $\mathbf{7 2}$ & $\mathbf{1 : 0 0}$ \\
5. Plate read & & \\
6. Melting curve & $\mathbf{7 0 - 9 5}$ & $\mathbf{0 : 0 1}$ \\
7. Cooling & $\mathbf{2 0}$ & $\infty$ \\
\hline
\end{tabular}

Back to 2. Repeat 39 times

$0,2{ }^{\circ} \mathrm{C} / \mathrm{s}$

Table S9: Real time quantitative PCR conditions for Microthrix parvicella

\begin{tabular}{|c|c|c|}
\hline & Temperature $\left[{ }^{\circ} \mathrm{C}\right]$ & Time [min:sec] \\
\hline 1. Pre-heating & 94 & $5: 00$ \\
\hline 2. Denaturation & 94 & $0: 45$ \\
\hline 3. Annealing & $\begin{array}{c}63\left(-0,5^{\circ} \mathrm{C} \text { per cy- }\right. \\
\text { cle })\end{array}$ & $0: 45$ \\
\hline 4. Elongation & 72 & $2: 00$ \\
\hline 5. Plate read & & \\
\hline 6. Denaturation & 94 & $0: 45$ \\
\hline 7. Annealing & 54 & $0: 45$ \\
\hline 8. Elongation & 72 & $0: 45$ \\
\hline 9. Plate read & & \\
\hline 10. Melting curve & 70-95 & 0:01 \\
\hline 11. Cooling & 20 & $\infty$ \\
\hline
\end{tabular}

Touchdown $63-54^{\circ} \mathrm{C}$

Back to 6. Repeat 17 times

$0,2{ }^{\circ} \mathrm{C} / \mathrm{s}$ 


\section{Quantitative fluorescence in-situ hybridization (qFISH) analysis:}

The samples were pre-treated and fixed with $4 \%$ paraformaldehyde and stored at $-20^{\circ} \mathrm{C}$ until qFISH analysis was done. 1-5 $\mu$ l of fixed sample were used for the analysis. The EUBmix probe, which comprises EUB338, EUB338-II and EUB338-III, was used to target total bacteria (Daims et al., 1999). Accumulibacter were targeted using PAOmix probes (PAO 651, 462 and 846, Crocetti et al., 2000) and Tetrasphaera were targeted with Actino221a and Actino-658a, together with the competitors per Kong et al. (2005). Competibacter were targeted using the GB probe by Kong et al. (2002). Defluviicoccus cluser I was targeted using probes TFO_DF218 and TFO_DF618 (Wong et al., 2004) and cluster II was targeted using probes DF988 and DF1020 combined with the helper probes per Meyer et al. (2006). A Leica SP5 confocal laser scanning microscope with a 20x objective was used to image the samples. As suggested by Nielsen et al. (2009), 20 randomly chosen images were taken and analysed using daime (digital image analysis in microbial ecology) software (Daime et al., 2006). 
Valverde-Pérez et al., 2016

Table S10: Probes for qFISH analysis

\begin{tabular}{|c|c|c|c|c|}
\hline Organism & Probe & Dye & Sequence $\left(5^{\prime} \rightarrow 3^{\prime}\right)$ & Reference \\
\hline Most Eubacteria & EUB338 & & GCTGCCTCCCGTAGGAGT & Amann et al., 1990 \\
\hline Planctomycetales & EUB338-II & Fluo (green) & GCAGCCACCCGTAGGTGT & Daims et al., 1999 \\
\hline Verrumicrobiales & EUB338-III & & GCTGCCACCCGTAGGTGT & Daims et al., 1999 \\
\hline \multirow{3}{*}{$\begin{array}{l}\text { Most Accumuli- } \\
\text { bacter }\end{array}$} & PAO462 & & CCGTCATCTACWCAGGGTATTAAC & \multirow{3}{*}{ Crocetti et al., 2000} \\
\hline & PAO651 & Cy3 (red) & СССТСТGCСАAАСТССАG & \\
\hline & PAO846 & & GTTAGCTACGGCACTAAAAGG & \\
\hline \multirow{6}{*}{$\begin{array}{l}\text { Actinobacteria } \\
\text { (Tetrasphaera) }\end{array}$} & Actino-221a & Cy5 (blue) & CGCAGGTCCATCCCAGAC & \multirow{6}{*}{ Kong et al., 2005} \\
\hline & c1Actino-221 & - & CGCAGGTCCATCCCATAC & \\
\hline & c2Actino-221 & - & CGCAGGTCCATCCCAGAG & \\
\hline & Actino-658a & Cy5 (blue) & TCCGGTCTCCССТАCCAT & \\
\hline & c1Actino-658 & - & TCCGGTCTCCCCTACCAC & \\
\hline & c2Actino-658 & - & ATTCCAGTCTCСССТАССАT & \\
\hline Competibacter & GB & Cy5 (blue) & CGATCCTCTAGCCCACT & Kong et al., 2002 \\
\hline \multirow{2}{*}{$\begin{array}{l}\text { Defluviicoccus } \\
\quad \text { (cluser I) }\end{array}$} & TFO_DF218 & \multirow{2}{*}{ Cy3 (red) } & GAAGCCTTTGCCCCTCAG & \multirow{2}{*}{ Wong et al., 2004} \\
\hline & TFO_DF618 & & GCCTCACTTGTCTAACCG & \\
\hline Defluviicoccus & DF988 & Cy3 (red) & GATACGACGCCCATGTCAAGGG & Meyer et al., 2006 \\
\hline
\end{tabular}

III - 56 
Valverde-Pérez et al., 2016

$\begin{array}{cccc}\text { (cluser II) } & \text { H966 } & - & \text { CTGGTAAGGTTCTGCGTTGC } \\ & \text { DF1020 } & \text { Cy3 }(\text { red }) & \text { CCGGCCGAACCGACTCCC }\end{array}$

H1038

AGCAGCCATGCAGCACCTGTGTGGCGT

III - 57 


\section{PCR amplification, pyrosequencing and bioinformatics analysis}

\subsection{PCR amplification and pyrosequencing}

10 ng of extracted DNA were PCR amplified using Phusion (Pfu) DNA polymerase (Finnzymes, Finland) and 16S rRNA gene targeted modified universal primers PRK341F (5'- CCTAYGGGRBGCASCAG-3') and PRK806R (5'GGACTACNNGGGTATCTAAT-3') to amplify the V3-V4 hypervariable region (Yu et al., 2005). PCR was performed as follows: an initial denaturation at $98{ }^{\circ} \mathrm{C}$ for $30 \mathrm{~s}, 30$ cycles of denaturation at $98^{\circ} \mathrm{C}$ for $5 \mathrm{~s}$, annealing at $56{ }^{\circ} \mathrm{C}$ for $20 \mathrm{~s}$ and elongation at $72{ }^{\circ} \mathrm{C}$ for $20 \mathrm{~s}$, and a final elongation step at $72{ }^{\circ} \mathrm{C}$ for 5 min. PCR products were analysed and cut from $1 \%$ agarose gel and purified by QIAEX II Gel Extraction Kit (QIAGEN). Sequencing was applied using the Illumina MiSeq platform at the DTU Multi Assay Core Center (Copenhagen, DK).

\subsection{Bioinformatics analysis}

The Paired End sequences from the raw fastq files supplied by Illumina Miseq were assembled using the pandaseq software (Masella et al., 2012). All assembled sequences shorter than $200 \mathrm{nts}$ and longer than $500 \mathrm{nts}$ were removed. The primers were also removed from the sequences. Chimeras were removed with UCHIME (Edgar et al., 2011) using default settings. After quality checks, all analyses were performed using QIIME 1.4.0 software (Caporaso et al., 2010). High quality sequences were clustered into OTUs at 97\% pairwise identity using the UCLUST algorithm (Edgar et al., 2011) with default settings, and representative sequences from each OTU were aligned against the Greengenes reference alignment (DeSantis et al., 2006) using PyNAST (Coporaso et al., 2010). Taxonomy assignment of each representative sequence was implemented using the BLAST algorithm (Altschul et al., 1997) against the Silva119 curated database. Unassigned sequences were re- 
moved from the sequence library and subsampling at depth of 11,800 sequences was performed to equalize sample sizes.

Canonical correspondence analysis (CCA) was used to examine the relationships of microbial communities and system performance variables. Significant correlations between specific taxa and phosphorus removal were confirmed with Pearson's product-moment correlation analysis. All statistical analysis were performed with the vegan package in $\mathrm{R}$ (The R Foundation, Vienna, Austria).

\subsection{Sulphate reducing bacteria diversity analysis} PCR was carried out with primers targeting dissimilatory sulphite reductase subunit-A (dsrA, Ben-Dov et al., 2007) and subunit-B (dsrB, Geets et al., 2006). PCR products were purified, after length verification, via agarose gel electrophoresis and cloned. 96 clones of both dsrA and dsrB PCR products were collected and grown. Finally, the plasmids containing the insert were isolated, purified and sequenced (Macrogen, Amsterdam, Nederland). Sequencing results were processed by locating inserts and eliminating repetitive sequences. Phylogenetic analysis was done using ClustalX multiple alignment software and MEGA phylogenetic tree construction software. 


\section{Microbial diversity analysis - pyrosequencing}

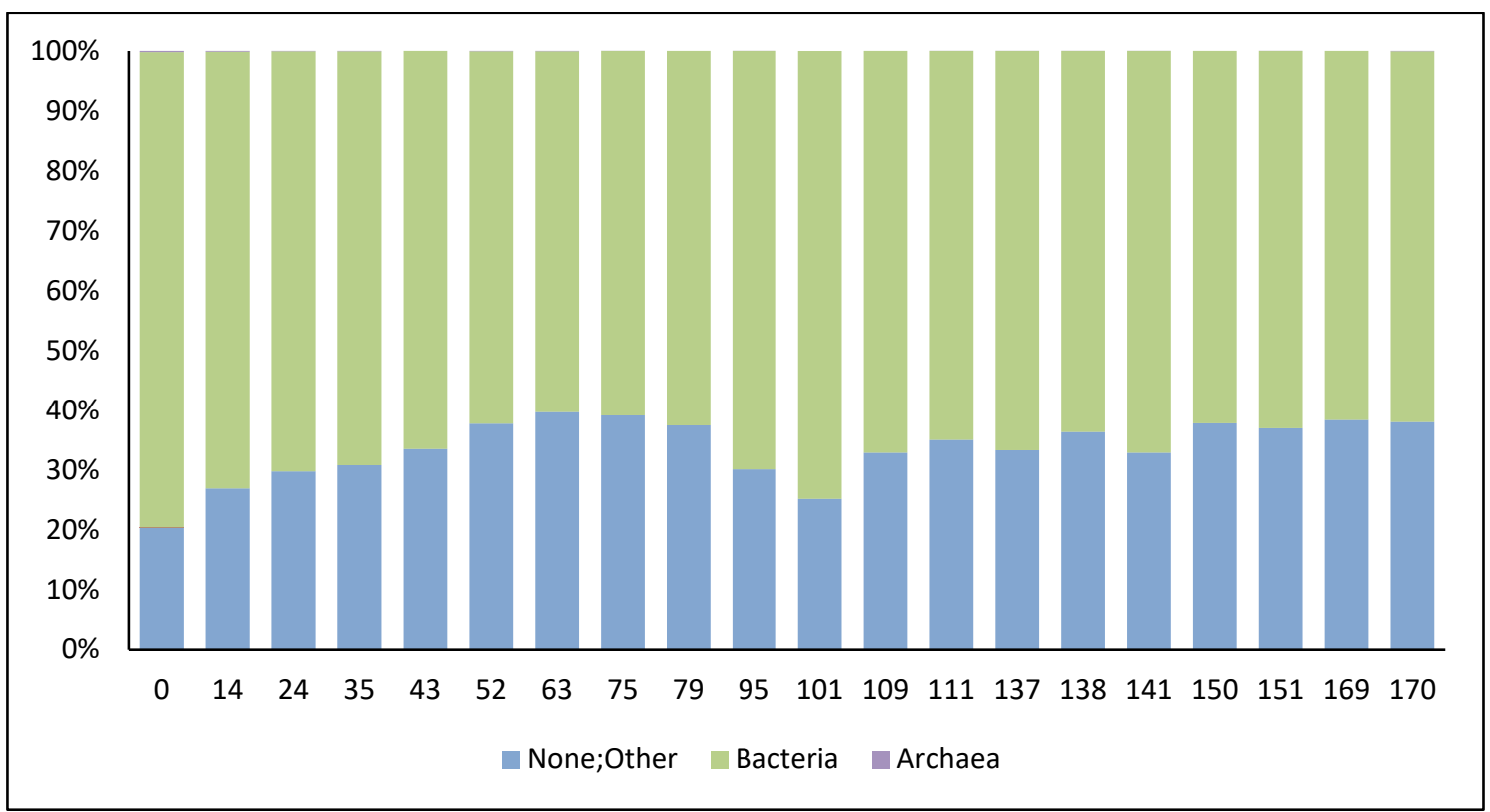

Figure S1: Domain-level taxonomic classification of 16S rRNA amplicons at selected time points of the reactor operation. Taxa abundance is expressed in percentage. 
Valverde-Pérez et al., 2016

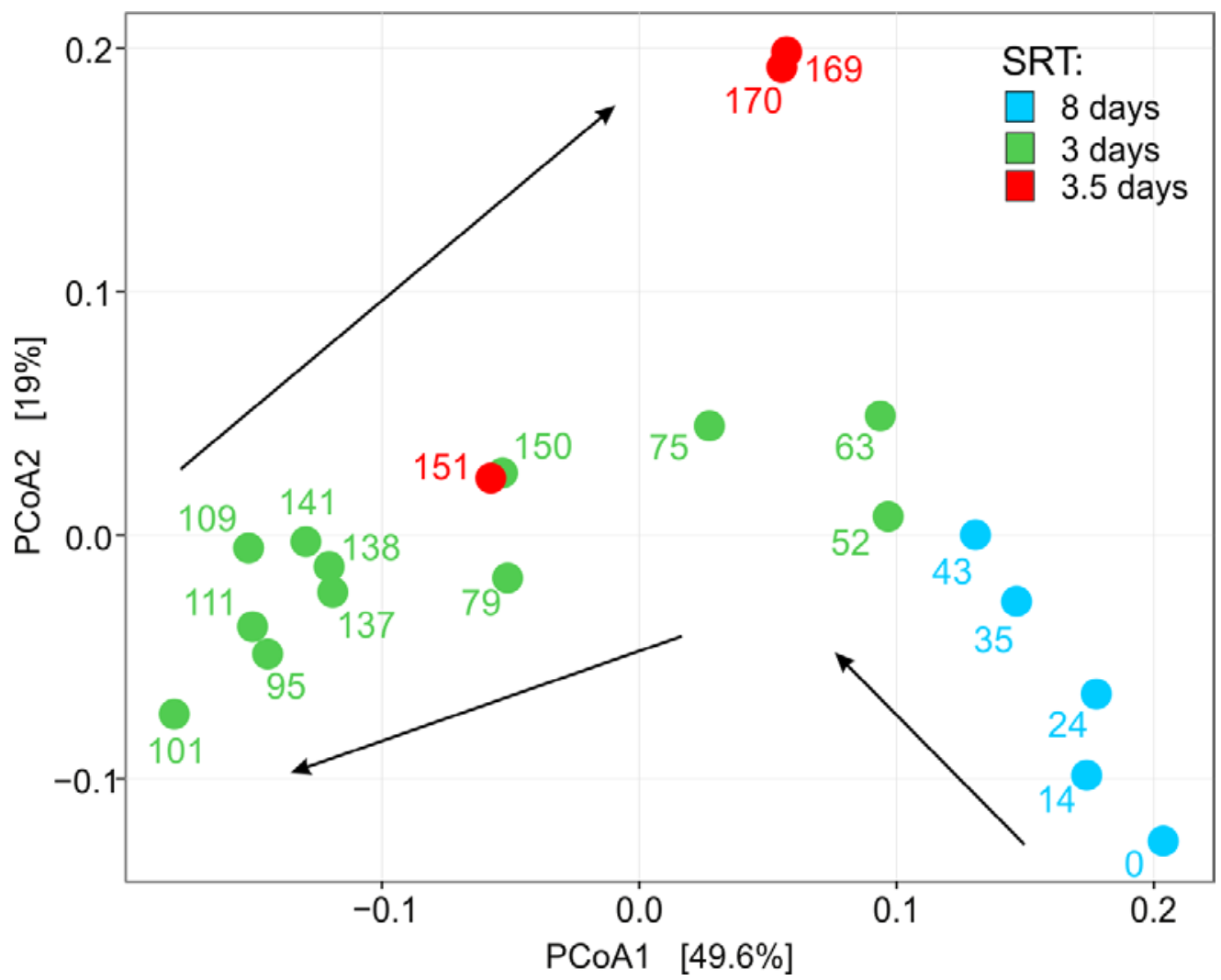

Figure S2: Phylogenetic distances between samples taken at different time points during reactor operation. The dissimilarity matrix was determined using Weighted UniFrac algorithm and plotted via principal coordinate analysis (PCoA). The percentage of variation explained by the principal coordinates is indicated on the axes.

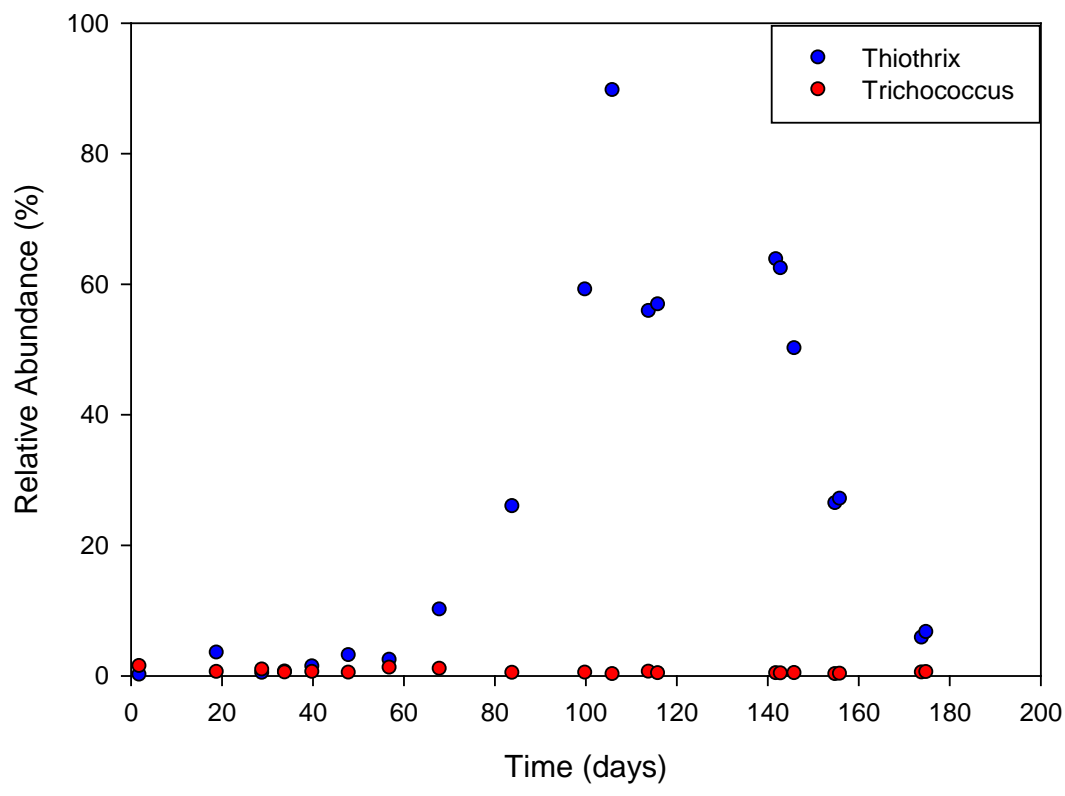

III - 61 
Figure S3: Relative abundance of filamentous bacteria along the operation of the short SRT EBPR. Only the 2 most abundant genera are shown.

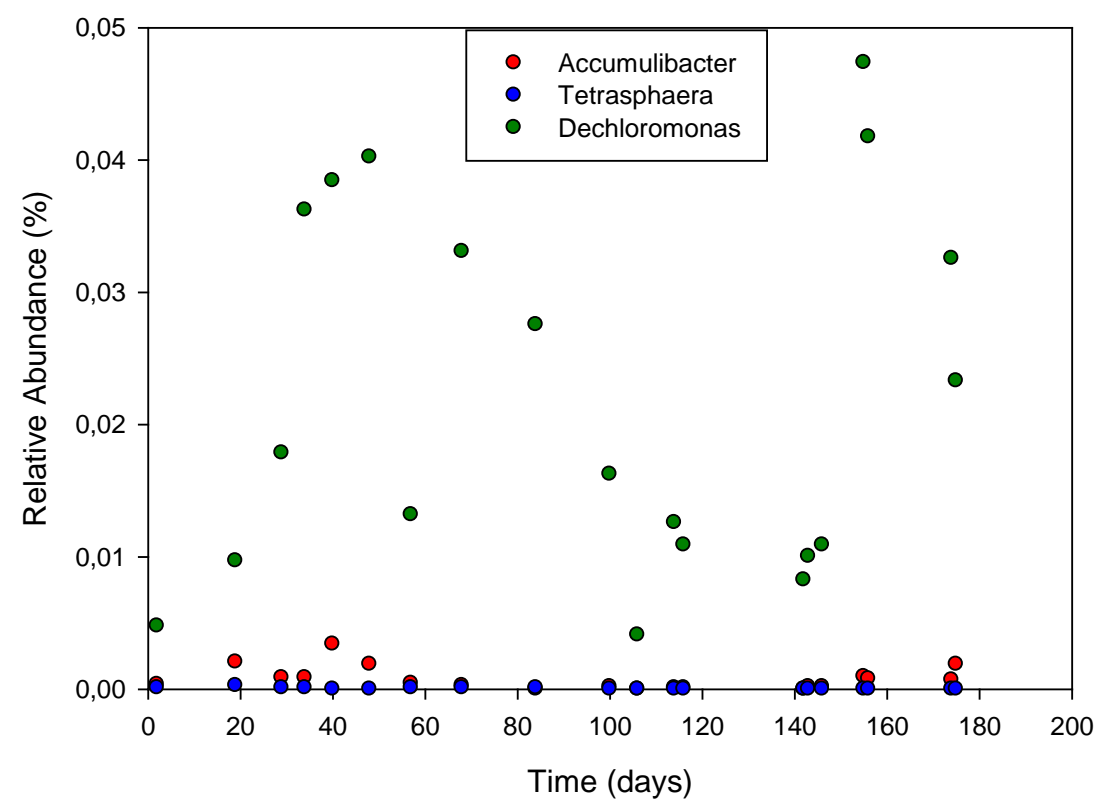

Figure S4: Relative abundance of PAO along the operation of the short SRT EBPR.

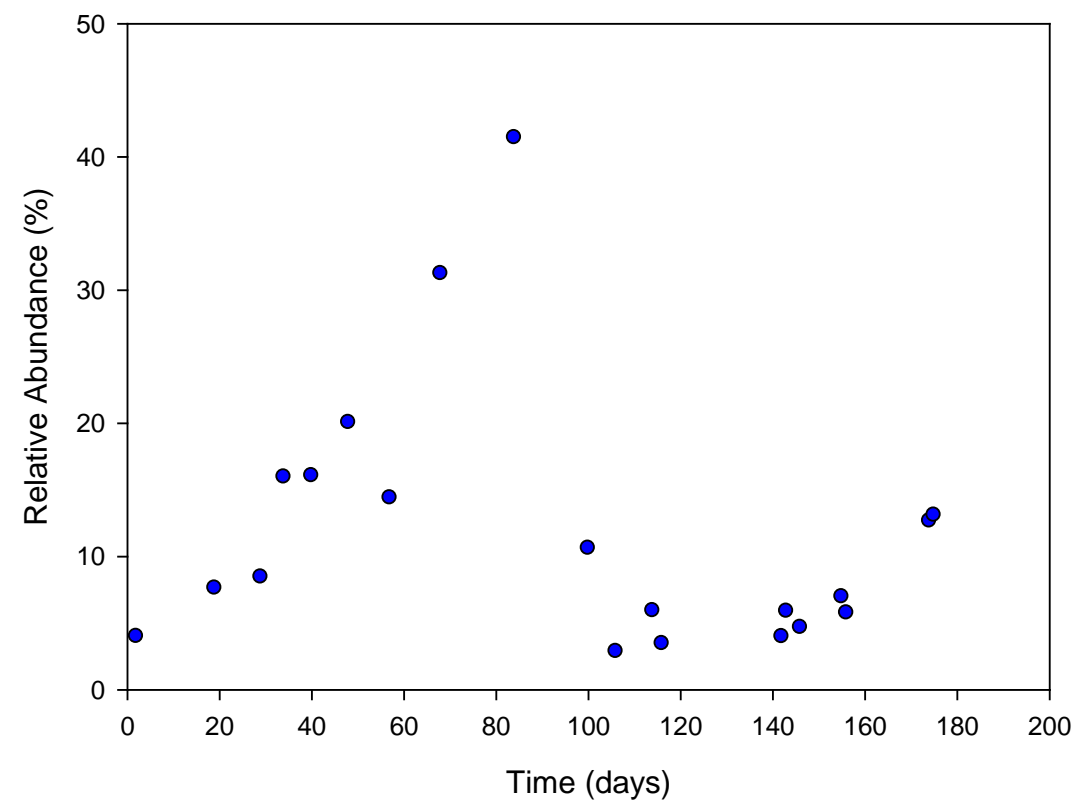

III - 62 
Valverde-Pérez et al., 2016

Figure S5: Relative abundance of Comamonadaceae along the operation of the short SRT EBPR.

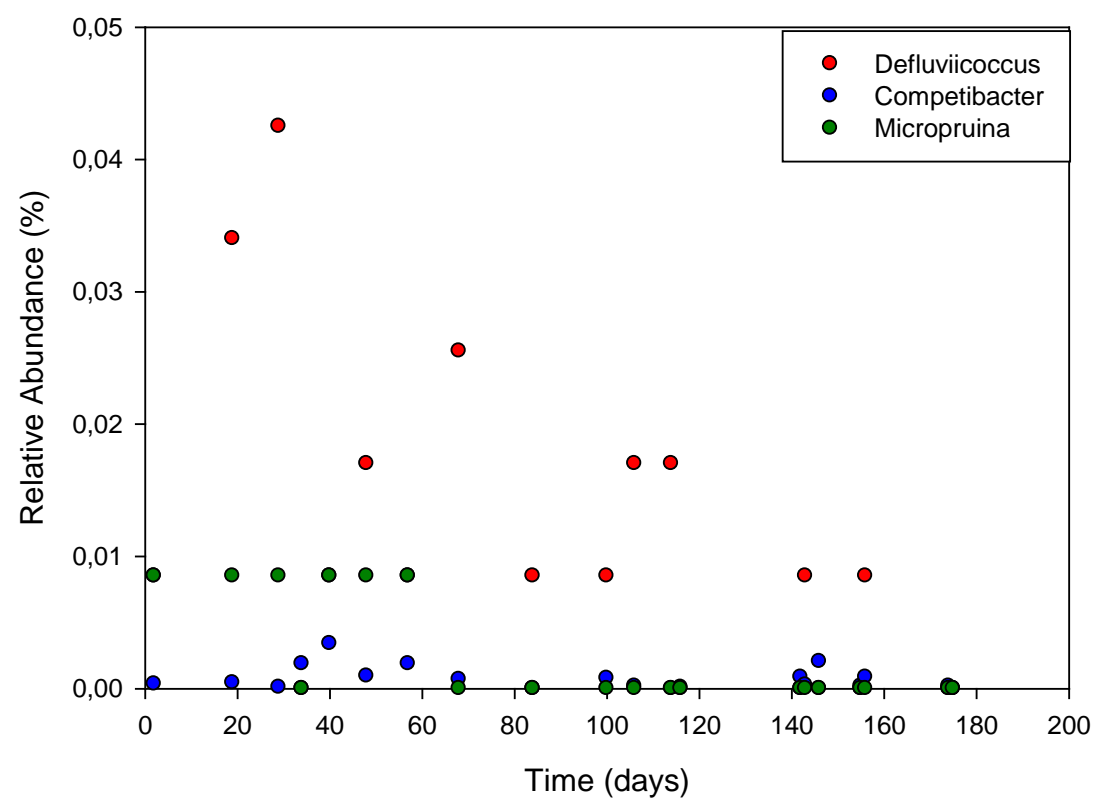

Figure S6: Relative abundance of GAO along the operation of the short-SRT EBPR.

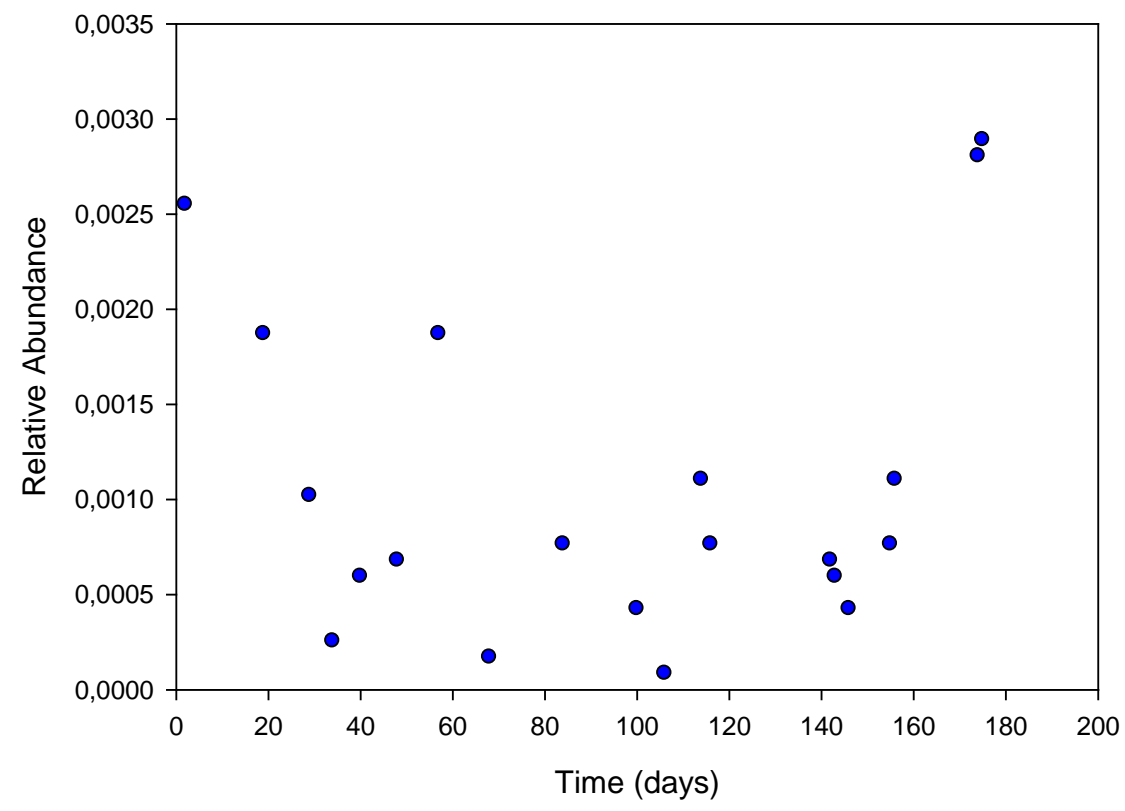

III - 63 
Valverde-Pérez et al., 2016

Figure S7: Relative abundance of SRBs along the operation of the short-SRT EBPR.

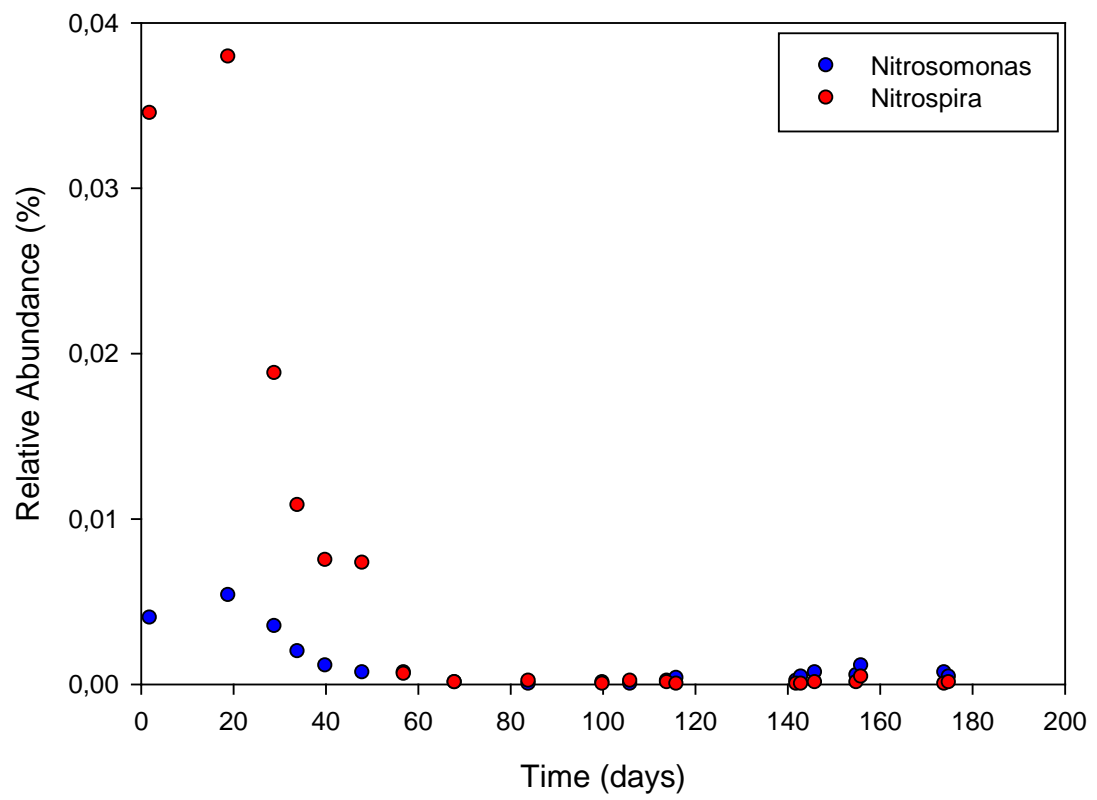

Figure S8: Relative abundance of AOB (Nitrosomonas) and NOB (Nitrospira) along the operation of the short-SRT EBPR. 
Valverde-Pérez et al., 2016

Table S11: Relative abundance of different bacterial group (\%) based on 16S rRNA gene amplicon sequencing results

\begin{tabular}{|c|c|c|c|c|c|c|c|c|c|c|c|c|}
\hline Days & Comamonadaceae & Trichococcus & Thiothrix & Accumulibacter & Tetrasphaera & Dechloromonas & Defluviicoccus & Competibacter & Micropurina & Nitrosomonas & Nitrospira & $S R B$ \\
\hline 2 & 3.9867 & 1.399 & 0.0594 & 3.40E-04 & $8.50 \mathrm{E}-05$ & 4.76E-03 & $8.50 \mathrm{E}-03$ & 3.40E-04 & $8.50 \mathrm{E}-03$ & 4.00E-03 & 0.0345 & $2.55 \mathrm{E}-03$ \\
\hline 19 & 7.608 & 0.5003 & 3.4509 & $2.04 \mathrm{E}-03$ & $2.55 \mathrm{E}-04$ & $9.69 \mathrm{E}-03$ & 0.034 & 4.25E-04 & $8.50 \mathrm{E}-03$ & $5.36 \mathrm{E}-03$ & 0.0379 & $1.87 \mathrm{E}-03$ \\
\hline 29 & 8.4495 & 0.8648 & 0.3392 & 8.50E-04 & $8.50 \mathrm{E}-05$ & 0.0179 & 0.0425 & $8.50 \mathrm{E}-05$ & $8.50 \mathrm{E}-03$ & 3.49E-03 & 0.0188 & $1.02 \mathrm{E}-03$ \\
\hline 34 & 15.9555 & 0.3985 & 0.5596 & 8.50E-04 & $8.50 \mathrm{E}-05$ & 0.0362 & 0 & $1.87 \mathrm{E}-03$ & 0 & 1.96E-03 & 0.0108 & $2.55 \mathrm{E}-04$ \\
\hline 40 & 16.0575 & 0.5003 & 1.3481 & 3.40E-03 & 0 & 0.0384 & $8.50 \mathrm{E}-03$ & $3.40 \mathrm{E}-03$ & $8.50 \mathrm{E}-03$ & $1.11 \mathrm{E}-03$ & $7.48 \mathrm{E}-03$ & $5.95 \mathrm{E}-04$ \\
\hline 48 & 20.0442 & 0.3815 & 3.0609 & $1.87 \mathrm{E}-03$ & 0 & 0.0402 & 0.017 & $9.35 \mathrm{E}-04$ & $8.50 \mathrm{E}-03$ & $6.80 \mathrm{E}-04$ & $7.31 \mathrm{E}-03$ & $6.80 \mathrm{E}-04$ \\
\hline 57 & 14.3829 & 1.1446 & 2.3656 & 4.25E-04 & $8.50 \mathrm{E}-05$ & 0.0132 & 8.50E-03 & 1.87E-03 & $8.50 \mathrm{E}-03$ & $6.80 \mathrm{E}-04$ & $5.95 \mathrm{E}-04$ & $1.87 \mathrm{E}-03$ \\
\hline 68 & 31.2224 & 0.9751 & 10.056 & 2.55E-04 & $8.50 \mathrm{E}-05$ & 0.0331 & 0.0255 & $6.80 \mathrm{E}-04$ & 0 & $8.50 \mathrm{E}-05$ & 8.50E-05 & $1.70 \mathrm{E}-04$ \\
\hline 84 & 41.423 & 0.3561 & 25.886 & 0 & $8.50 \mathrm{E}-05$ & 0.0275 & $8.50 \mathrm{E}-03$ & 0 & 0 & 0 & 1.70E-04 & 7.65E-04 \\
\hline 100 & 10.6001 & 0.3731 & 59.0894 & 1.70E-04 & 0 & 0.0162 & 8.50E-03 & 7.65E-04 & 0 & $8.50 \mathrm{E}-05$ & 0 & $4.25 \mathrm{E}-04$ \\
\hline 106 & 2.8562 & 0.1611 & 89.6134 & 0 & 0 & $4.08 \mathrm{E}-03$ & 0.017 & $1.70 \mathrm{E}-04$ & 0 & 0 & $1.70 \mathrm{E}-04$ & $8.50 \mathrm{E}-05$ \\
\hline 142 & 3.9782 & 0.3052 & 63.7273 & 0 & 0 & $8.25 \mathrm{E}-03$ & 0 & $8.50 \mathrm{E}-04$ & 0 & $1.70 \mathrm{E}-04$ & 0 & $6.80 \mathrm{E}-04$ \\
\hline 143 & 5.8824 & 0.2713 & 62.3368 & 1.70E-04 & 0 & 0.01 & $8.50 \mathrm{E}-03$ & $2.55 \mathrm{E}-04$ & 0 & 4.25E-04 & 0 & $5.95 \mathrm{E}-04$ \\
\hline 114 & 5.9164 & 0.5087 & 55.7741 & 8.50E-05 & 0 & 0.0126 & 0.017 & 0 & 0 & $1.70 \mathrm{E}-04$ & 8.50E-05 & $1.11 \mathrm{E}-03$ \\
\hline 146 & 4.6668 & 0.3307 & 50.0933 & 1.70E-04 & 0 & 0.0109 & 0 & $2.04 \mathrm{E}-03$ & 0 & $6.80 \mathrm{E}-04$ & 8.50E-05 & $4.25 \mathrm{E}-04$ \\
\hline 116 & 3.4512 & 0.2968 & 56.8085 & $8.50 \mathrm{E}-05$ & 0 & 0.0109 & 0 & $8.50 \mathrm{E}-05$ & 0 & $3.40 \mathrm{E}-04$ & 0 & $7.65 \mathrm{E}-04$ \\
\hline 155 & 6.9704 & 0.1526 & 26.3354 & $9.35 \mathrm{E}-04$ & 0 & 0.0473 & 0 & $1.70 \mathrm{E}-04$ & 0 & $5.10 \mathrm{E}-04$ & $8.50 \mathrm{E}-05$ & $7.65 \mathrm{E}-04$ \\
\hline 156 & 5.7548 & 0.2035 & 27.0307 & 7.65E-04 & 0 & 0.0417 & $8.50 \mathrm{E}-03$ & 8.50E-04 & 0 & $1.11 \mathrm{E}-03$ & 4.25E-04 & $1.11 \mathrm{E}-03$ \\
\hline 174 & 12.6488 & 0.407 & 5.7402 & $6.80 \mathrm{E}-04$ & 0 & 0.0326 & 0 & 1.70E-04 & 0 & $6.80 \mathrm{E}-04$ & 0 & $2.81 \mathrm{E}-03$ \\
\hline 175 & 13.0908 & 0.4579 & 6.622 & $1.87 \mathrm{E}-03$ & 0 & 0.0233 & 0 & 0 & 0 & 4.25E-04 & $8.50 E-05$ & $2.89 \mathrm{E}-03$ \\
\hline
\end{tabular}




\subsection{Complementary information about microbial diversity analysis - qPCR and qFISH}

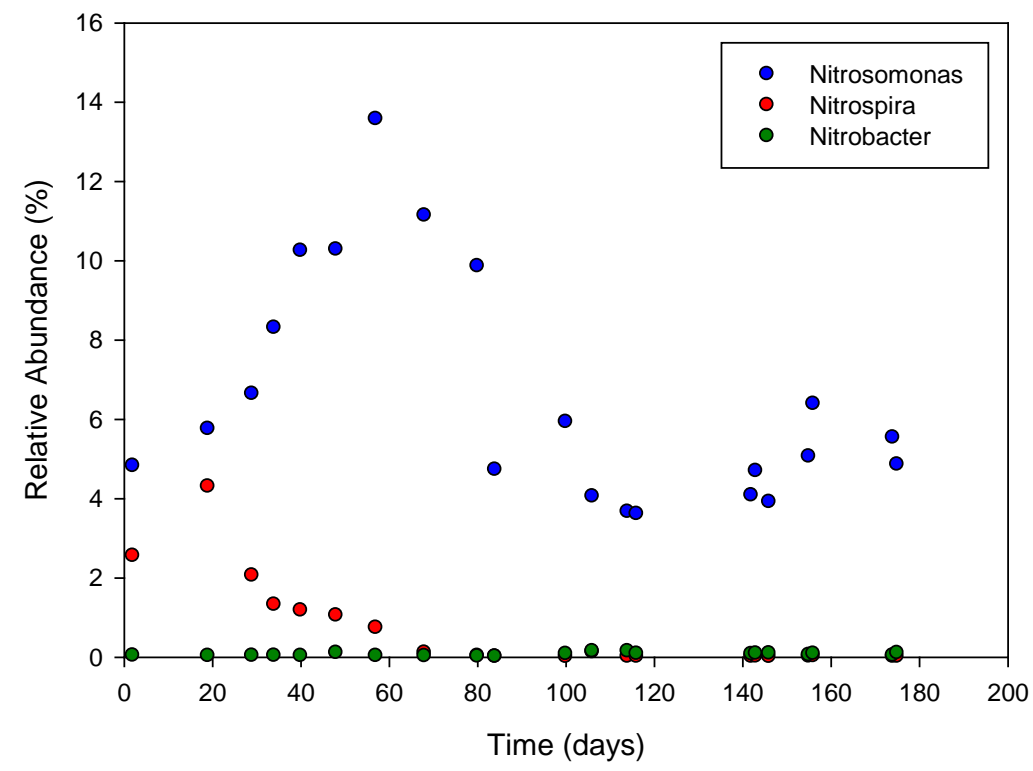

Figure S9: Relative abundance of AOBs along the operation of the short-SRT EBPR according to qPCR.

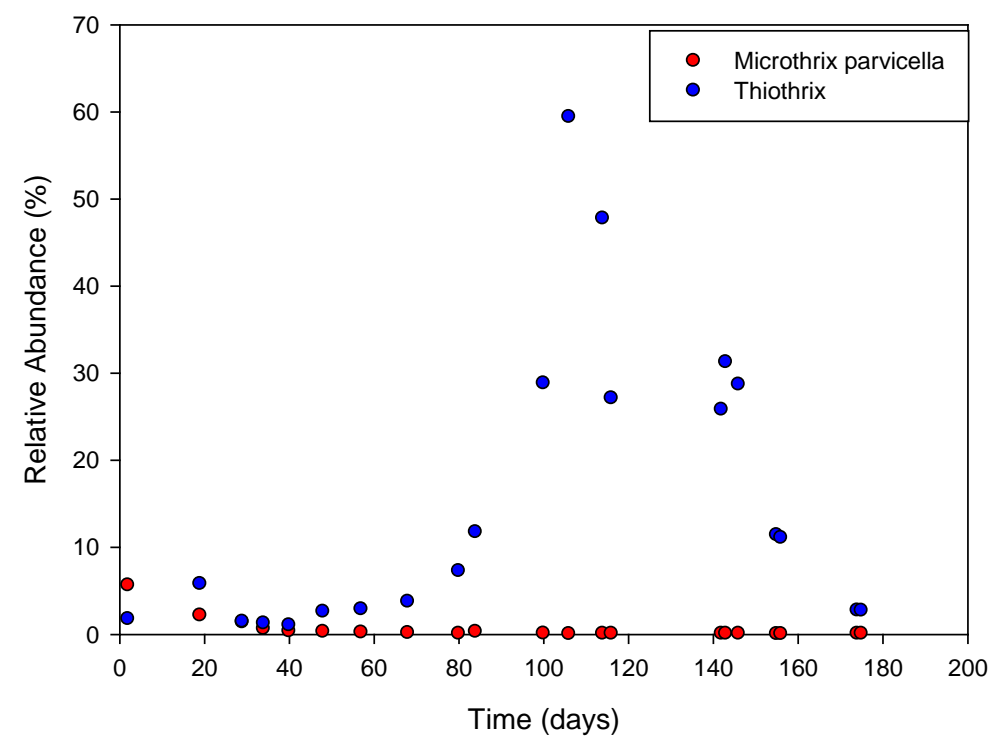

III - 66 
Valverde-Pérez et al., 2016

Figure S10: Relative abundance of filamentous bacteria along the operation of the shortSRT EBPR.

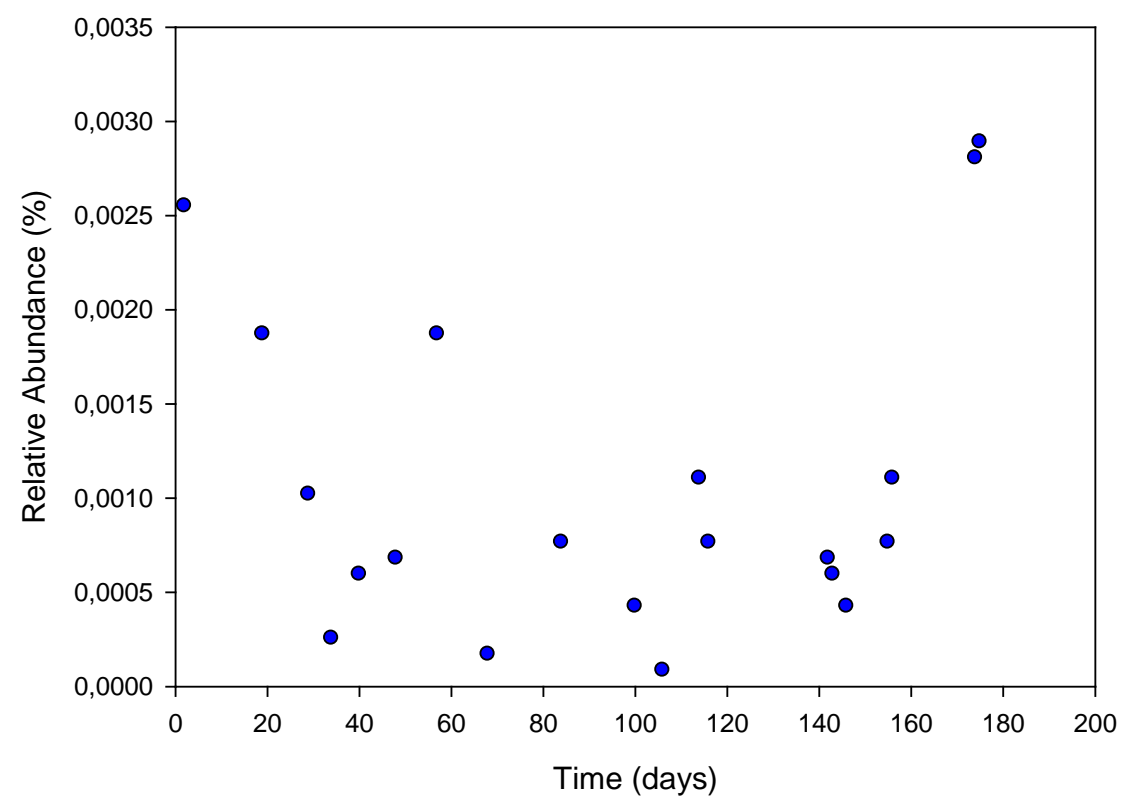

Figure S11: Relative abundance of SRB along the operation of the short-SRT EBPR.

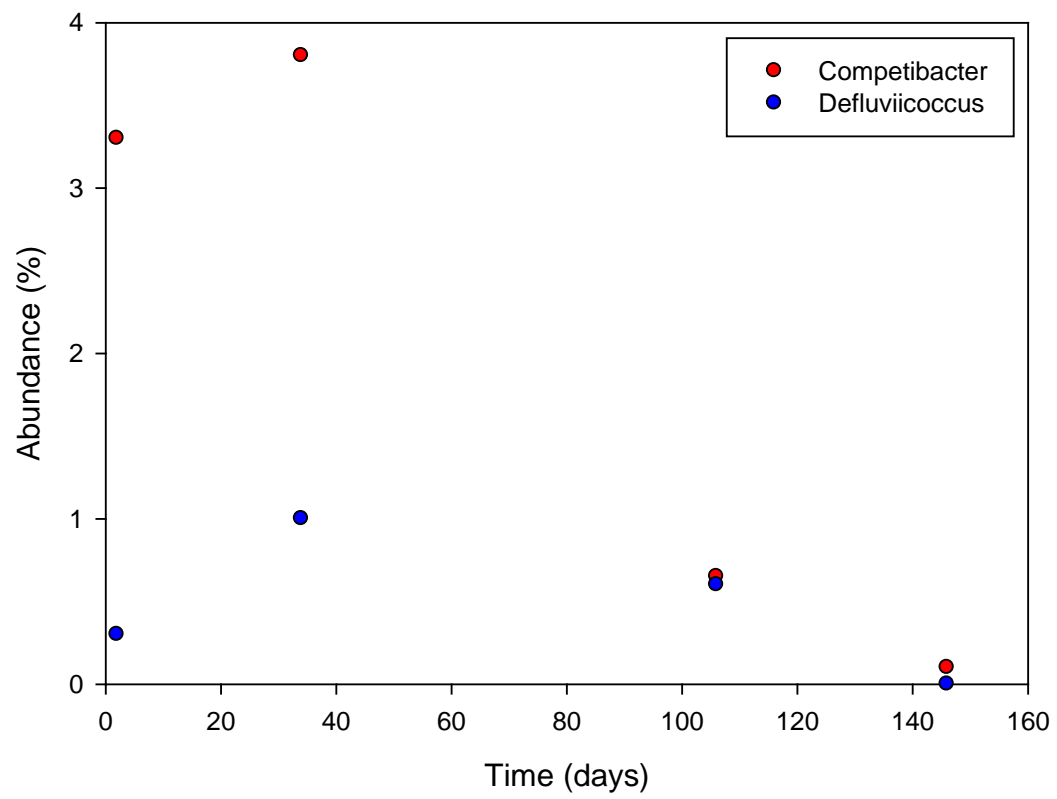

Figure S12: Relative abundance of GAO along the operation of the short-SRT EBPR. 
Valverde-Pérez et al., 2016

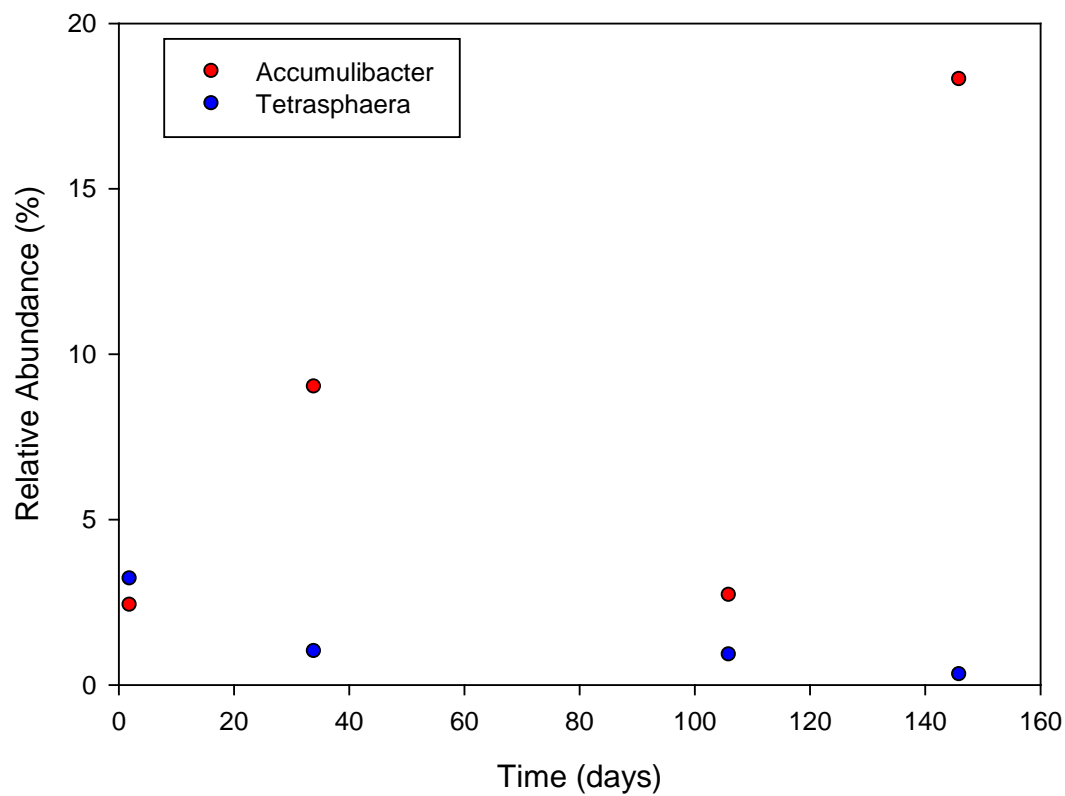

Figure S13: Relative abundance of PAO along the operation of the short-SRT EBPR. 
Valverde-Pérez et al., 2016

Table S12: Relative abundance of different bacterial group (\%) based on qPCR results (Nitrosomonas, Nitrospira, Nitrobacter, SRB, Thiothrix and M. parvicella) and qFISH (Accumulibacter, Tetrasphaera, Competibacter and Defluviicoccus)

\begin{tabular}{|c|c|c|c|c|c|c|c|c|c|c|}
\hline Day & Nitrosomonas & Nitrospira & Nitrobacter & SRBS & Thiothrix & M. parvicella & Accumulibacter & Tetrasphaera & Competibacter & Defluviicoccus \\
\hline 2 & 4.823 & 2.5536 & 0.0392 & 0.0564 & 1.7425 & 5.6137 & 2.4 & 3.2 & 3.3 & 0.3 \\
\hline 19 & 5.7574 & 4.2993 & 0.0313 & 0.0587 & 5.7705 & 2.1711 & & & & \\
\hline 29 & 6.6415 & 2.0573 & 0.0333 & 0.0505 & 1.446 & 1.3702 & & & & \\
\hline 34 & 8.3073 & 1.3198 & 0.0346 & 0.0319 & 1.263 & 0.6238 & 9 & 1 & 3.8 & 1 \\
\hline 40 & 10.2485 & 1.1758 & 0.0304 & 0.0174 & 1.0369 & 0.3513 & & & & \\
\hline 48 & 10.2796 & 1.0503 & 0.1078 & 0.0261 & 2.5889 & 0.2784 & & & & \\
\hline 57 & 13.5748 & 0.7399 & 0.0314 & 0.0483 & 2.8757 & 0.2162 & & & & \\
\hline 68 & 11.1407 & 0.1112 & 0.0254 & 0.0812 & 3.7466 & 0.1475 & & & & \\
\hline 80 & 9.8615 & 0.0313 & 0.0166 & 0.0379 & 7.2613 & 0.0743 & & & & \\
\hline 84 & 4.7277 & 0.0131 & 0.0104 & 0.0377 & 11.7324 & 0.2807 & & & & \\
\hline 100 & 5.9333 & 5.97E-03 & 0.0807 & 0.053 & 28.8205 & 0.0879 & & & & \\
\hline 106 & 4.0536 & 0.1241 & 0.1455 & 0.0193 & 59.4082 & 0.0219 & 2.7 & 0.9 & 0.65 & 0.6 \\
\hline 142 & 4.0811 & 0.0128 & 0.0765 & 0.0849 & 25.7995 & 0.0693 & & & & \\
\hline 143 & 4.6925 & 0.0149 & 0.087 & 0.0822 & 31.2367 & 0.0649 & & & & \\
\hline 114 & 3.6659 & $9.84 \mathrm{E}-03$ & 0.1477 & 0.0439 & 47.7505 & 0.0698 & & & & \\
\hline 146 & 3.9116 & $7.46 \mathrm{E}-03$ & 0.0932 & 0.0331 & 28.6741 & 0.0604 & 18.3 & 0.3 & 0.1 & 0 \\
\hline 116 & 3.6107 & 0.0124 & 0.0856 & 0.0597 & 27.0951 & 0.0609 & & & & \\
\hline 155 & 5.0606 & 0.0163 & 0.0524 & 0.0384 & 11.3805 & 0.0364 & & & & \\
\hline 156 & 6.3885 & 0.0244 & 0.0843 & 0.0438 & 11.0835 & 0.0348 & & & & \\
\hline 174 & 5.5366 & 0.0131 & 0.0386 & 0.1249 & 2.732 & 0.0615 & & & & \\
\hline 175 & 4.855 & 0.0117 & 0.0998 & 0.1167 & 2.7143 & 0.0682 & & & & \\
\hline
\end{tabular}

III - 69 


\subsection{Microbial diversity of sulphate reducing bacteria}

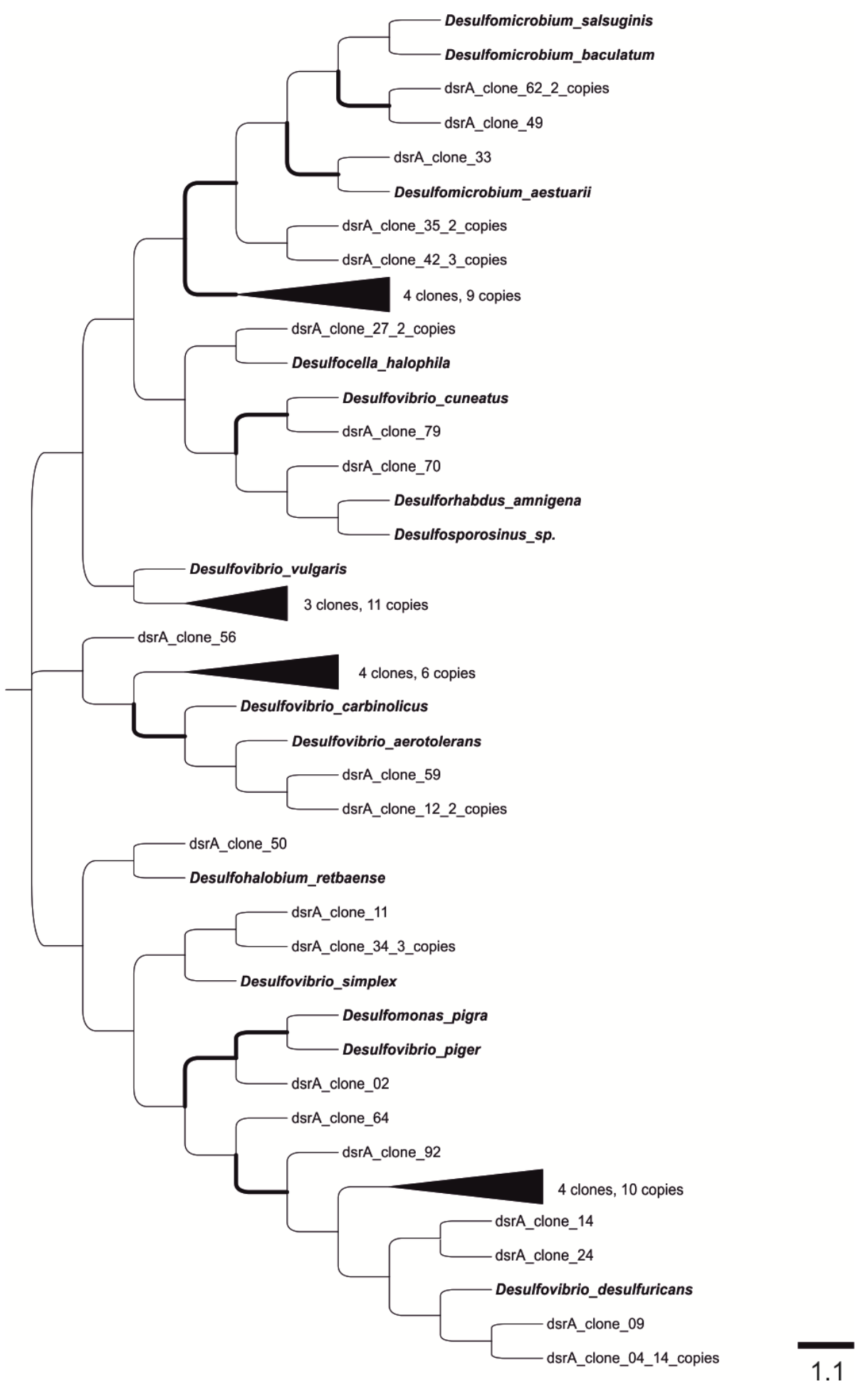

Figure S14: Phylogenetic tree of the cloned $d s r A$ genes in the investigated reactor samples. The tree was constructed using the Kimura algorithm in MEGA with 1,000 bootstrap replicates. The percentage of replicate trees $(>60 \%)$ are shown by thick branches. The scale bar represents 1.1 substitutions per nucleotide position. 


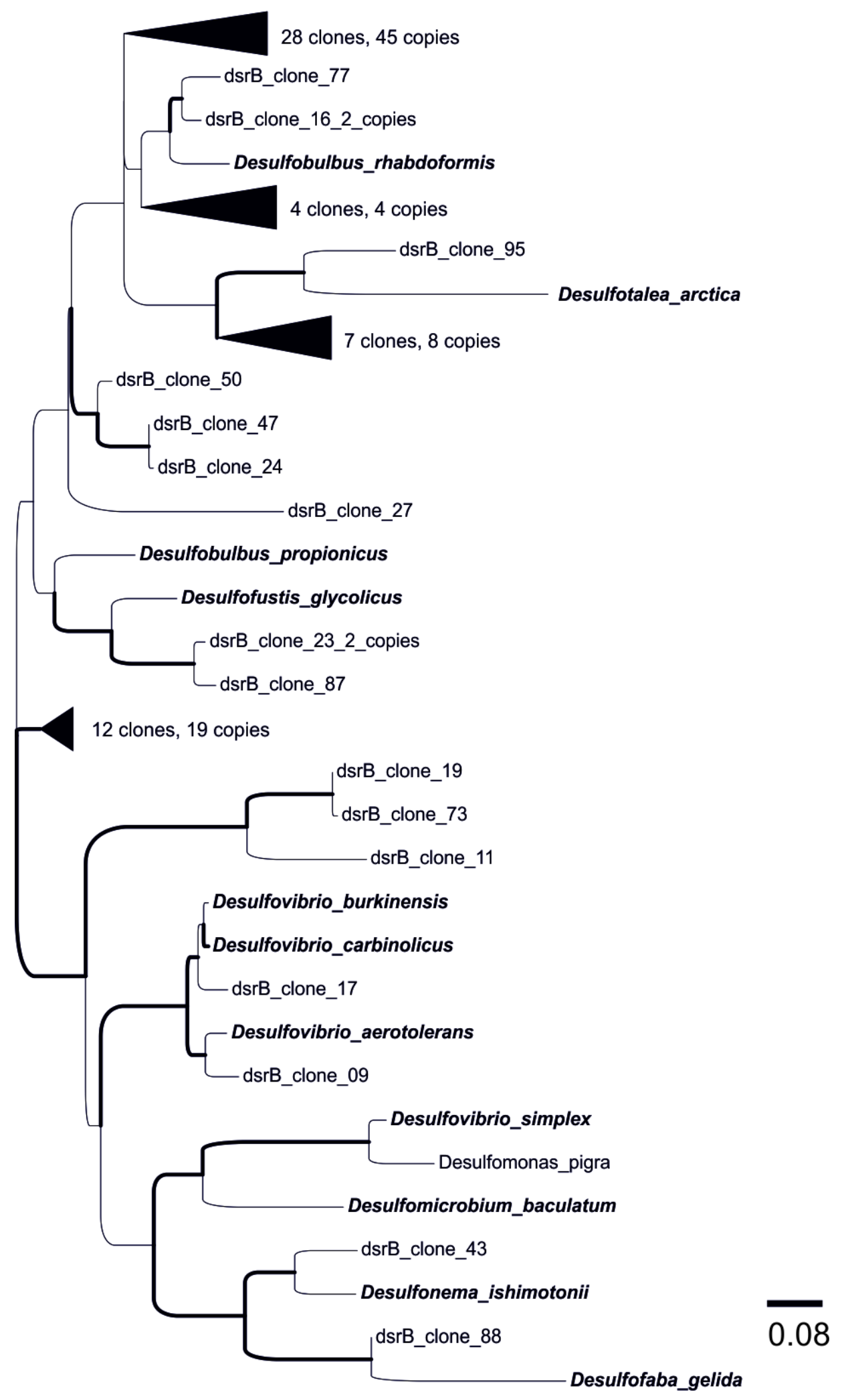

Figure S15: Phylogenetic tree of the cloned $d s r B$ genes in the investigated reactor samples. The tree was constructed using the TN93 algorithm in MEGA with 1,000 bootstrap replicates. The percentage of replicate trees $(>60 \%)$ are shown by thick branches. The scale bar represents 0.08 substitutions per nucleotide position. 


\subsection{Microbial community composition from sequencing quantified by targeting the $16 \mathrm{~S}$ based primers and probes used for qFISH and qPCR}

Table S13: Microbial community composition based on amplicon sequencing abundance inferred by targeting the 16S based primers and probes used for qFISH and qPCR

\begin{tabular}{|c|c|c|c|c|c|c|c|c|c|c|}
\hline Days & PAO462 & PAO651 & PAO846 & Actino-221a & Actino-658a & TFO_DF218 & TFO_DF618 & GB & DF988 & DF1020 \\
\hline 2 & 0.1759 & 0 & 0 & 0 & 0.5228 & 0 & 0 & 2.62 & 0 & 0 \\
\hline 19 & 0.36954 & 0 & 0 & 0 & 0.2411 & 0 & 0 & 4.93 & 0 & 0 \\
\hline 29 & 0.31114 & 0 & 0 & 0 & 0.1229 & 0 & 0 & 5.85 & 0 & 0 \\
\hline 34 & 0 & 0 & 0 & 0 & 0 & 0 & 0 & 0 & 0 & 0 \\
\hline 40 & 0.00861 & 0 & 0 & 0 & 0.0017217 & 0 & 0 & 1.19 & 0 & 0 \\
\hline 48 & 0.70822 & 0 & 0 & 0 & 0.0605 & 0 & 0 & 5.97 & 0 & 0 \\
\hline 57 & 0.2747 & 0 & 0 & 0 & 0.0201 & 0 & 0 & 5.05 & 0 & 0 \\
\hline 68 & 0.04348 & 0 & 0 & 0 & 0.0072466 & 0 & 0.0036 & 4.54 & 0 & 0 \\
\hline 80 & 0.01826 & 0 & 0 & 0 & 0.0104 & 0 & 0 & 2.26 & 0 & 0 \\
\hline 84 & 0.01114 & 0 & 0 & 0 & 0 & 0 & 0 & 1.59 & 0 & 0 \\
\hline 100 & 0.10559 & 0 & 0 & 0 & 0.0679 & 0 & 0 & 7.39 & 0 & 0 \\
\hline 106 & 0.00889 & 0 & 0 & 0 & 0 & 0 & 0 & 0.32 & 0 & 0 \\
\hline 142 & 0.05702 & 0 & 0 & 0 & 0 & 0 & 0.0023 & 0.66 & 0 & 0 \\
\hline 143 & 0.06485 & 0 & 0 & 0 & 0 & 0 & 0 & 0.44 & 0 & 0 \\
\hline 114 & 0.02416 & 0 & 0 & 0 & 0.0034508 & 0 & 0 & 0.37 & 0 & 0 \\
\hline 146 & 0.04966 & 0 & 0 & 0 & 0 & 0 & 0 & 0.51 & 0 & 0 \\
\hline 116 & 0.03791 & 0 & 0 & 0 & 0.0023692 & 0 & 0.0047 & 0.55 & 0 & 0 \\
\hline 155 & 0.05344 & 0 & 0 & 0 & 0.0044536 & 0 & 0 & 0.47 & 0 & 0 \\
\hline 156 & 0.06137 & 0 & 0 & 0 & 0 & 0 & 0 & 0.54 & 0 & 0 \\
\hline 174 & 0.20401 & 0 & 0 & 0 & 0 & 0 & 0 & 0.14 & 0 & 0 \\
\hline 175 & 0,34683 & 0 & 0 & 0 & 0.0074588 & 0 & 0 & 0.15 & 0 & 0 \\
\hline
\end{tabular}

III - 72 


\section{Relation between sulphate reduction and 2 phosphate removal}

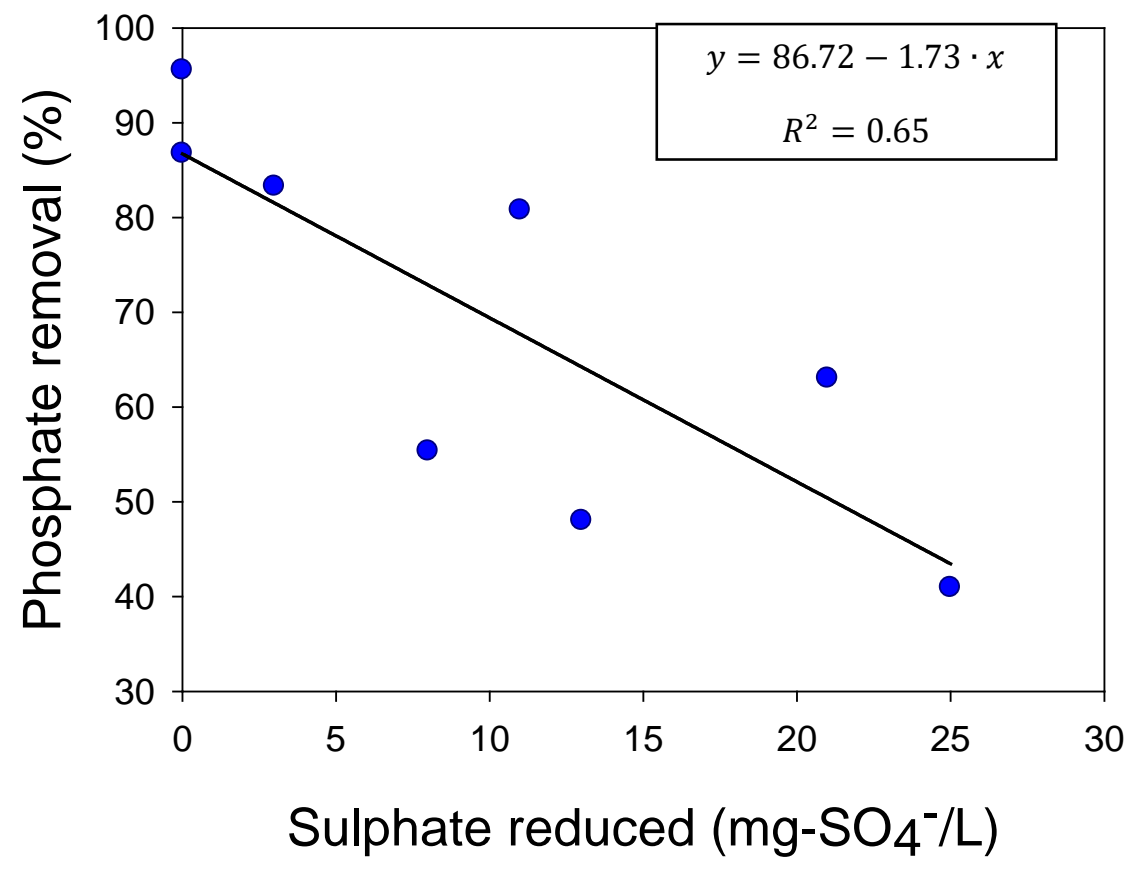

Figure S16: Correlation between sulphate reduced along the anaerobic phase and phosphorus removal. 5 


\section{Relation between Thiothrix and sludge volume index (SVI)}

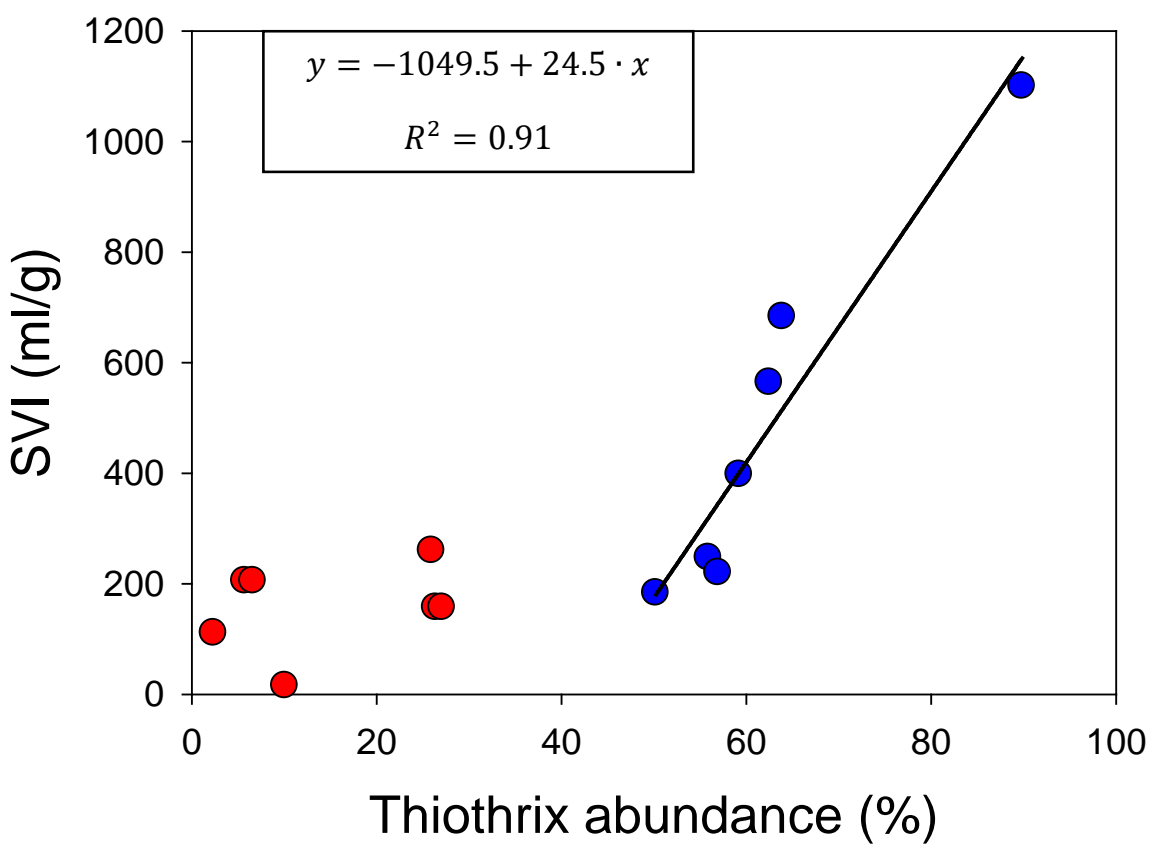

9 Figure S17: Correlation between SVI and Thiothrix abundance. Abundance lower than 50\% is shown 10 in red was excluded from the linear regression analysis. 
13 COD consumption by denitrifiers and SRB and uptake rates used in the discussion

\begin{tabular}{|c|c|c|}
\hline & Parameters & Calculation \\
\hline $\begin{array}{l}\text { COD consumption } \\
\text { by denitrifiers }\end{array}$ & $\begin{aligned} \mathrm{Y}_{\mathrm{H}}= & 0.625 \mathrm{~g}-\mathrm{COD} \cdot \mathrm{g}-\mathrm{COD}^{-1} \\
& (\text { Henze et al.1999) }\end{aligned}$ & $\Delta S_{N O 3} \frac{\frac{1-Y_{H}}{2.86 \cdot Y_{H}}}{\frac{1}{Y_{H}}}$ \\
\hline $\begin{array}{l}\text { COD consumption } \\
\text { by SRB }\end{array}$ & $\begin{array}{c}\mathrm{Y}_{\mathrm{Pr} / \mathrm{SO} 4}=1.333 \text { mol-propionate/mol-SO } \\
\text { (Yamamoto-Ikemoto et al., 1996) }\end{array}$ & $\Delta S_{S O 4} \cdot Y_{P r / S O 4}$ \\
\hline $\begin{array}{l}\text { Specific uptake } \\
\text { rate for SRB }\end{array}$ & $\begin{array}{c}\mathrm{Y}_{\mathrm{X} / \mathrm{Pr}}=0.026 \mathrm{~g}-\mathrm{COD} \cdot \mathrm{g}-\mathrm{COD}^{-1} \\
\mu_{\max }=0.29 \mathrm{~d}^{-1} \\
\text { (Cassidy et al., 2015) }\end{array}$ & $\frac{1}{Y_{X / P r}} \mu_{\max }$ \\
\hline $\begin{array}{l}\text { Specific uptake } \\
\text { rate for PAO un- } \\
\text { der anaerobic } \\
\text { conditions }\end{array}$ & $\begin{array}{l}\text { qРHA }=3 \text { g-COD } \cdot g-C O D \\
\text { (Henze et al., 1999) }\end{array}$ & - \\
\hline
\end{tabular}


$20 \quad$ 14 References

21 Altschul, S.F., Madden, T.L., Schäffer , A.A., Zhang, J., Zhang, Z., Miller, W., Lipman, D.J., 1997. Gapped BLAST and PSI-BLAST: a new generation of protein database search programs. Nucleic Acids Research 25, 3389-402.

Caporaso JG, Kuczynski J, Stombaugh J, Bittinger K, Bushman FD, Costello EK, Fierer N, Peña AG, Goodrich JK, Gordon JI, Huttley GA, Kelley ST, Knights D, Koenig JE, Ley RE, Lozupone CA, Mcdonald D, Muegge BD, Pirrung M, Reeder J, Sevinsky JR, Turnbaugh PJ, Walters WA, Widmann J, Yatsunenko T, Zaneveld J, Knight R., 2010. QIIME allows analysis of high- throughput community sequencing data. Nature Methods 7, 335-336.

Caporaso JG, Bittinger K, Bushman FD, DeSantis TZ, Andersen GL, Knight R. 2010. PyNAST: a flexible tool for aligning sequences to a template alignment. Bioinformatics 26, 266-267.

Cassidy, J., Lubberding, H.J., Esposito, G., Keesman, K.J., Lens, P.N.L., 2015. Automated biological sulphate reduction: a review on mathematical models, monitoring and bioprocess control. FEMS Microbiology Reviews, 39, 823-853.

Crocetti, G.R., Hugenholtz, P., Bond, P.L., Schuler, A., Keller, J., Jenkins, D., Blackall, L.L., 2000. Identification of polyphosphate-accumulating organisms and design of 16S rRNAdirected probes for their detection and quantitation. Applied Environmental Microbiology, 66 (3), 1175-1182.

Daims, H., Lücker, S., Wagner, M., 2006. Daime, a novel image analysis program for microbial ecology and biofilm research. Environmental Microbiology, 8(2), 200213.

DeSantis, T.Z., Hugenholtz, P., Larsen, N., Rojas, M., Brodie, E.L., Keller, K., Huber, T., Dalevi, D., Hu, P., Andersen, G.L., 2006. Greengenes, a chimera-checked 16S 
rRNA gene database and workbench compatible with ARB. Applied Environmental Microbiology, 72, 5069-5072.

Edgar, R.C., Haas, B.J., Clemente, J.C., Quince, C., Knight, R., 2011. UCHIME improves sensitivity and speed of chimera detection. Bioinformatics 27, 2194-2200.

Ferris, M.J., Muyzer, G., Mard, D.M., 1996. Denaturing gradient gel electrophoresis profiles of 16S rRNA-defined populations inhabiting a hot spring microbial mat community. Applied and Environmental Microbiology, 62, 340-346.

Henze, M., Gujer, W., Mino, T., Matsuo, T., Wentzel, M.C., Marais, G.V.R., Van Loosdrecht, M.C.M., 1999. Activated sludge model nº 2d, ASM2d. Water Science and Technology, 39, 165-182.

Hermansson, A., Lindgren, P.E., 2001. Quantification of ammonia oxidizing bacteria in arable soil by real-time PCR. Applied Environmental Microbiology, 67, 972-976.

Karkhoff-Scheizer, R.R., Huber, D.P.W., Voordouw, G., 1995. Conservation of the genes for dissimilatory sulphite reductase from Desulfovibrio vulgaris and Archaeoglobus fulgidus allows their detection by PCR. Applied and Environmental Microbiology, 61(1), 290-296.

Kaetzke, A., Jentzsch, D., Eschrich, K., 2005. Quantification of Microthrix parvicella in activated sludge bacterial conmmunities by real-time PCR. Letters in Applied Microbiology, 40, 207-211.

Kong, Y.H., Ong, S.L., Ng, W.J., Liu, W.T., 2002. Diversity and distribution of a deeply branched novel proteobacterial group found in anaerobic-aerobic activated sludge processes. Environmental Microbiology, 4 (11), 753-757.

Kong, Y.H., Nielsen, J.L., Nielsen, P.H., 2005. Identity and ecophysiology of uncultured actinobacterial polyphosphate-accumulating organisms in full-scale enhanced biological phosphorus removal plants. Applied Environmental Microbiology, 71 (7), 4076-4085. 
71 Kowalchuk, G.A., Stephen, J. R., De Boer, W., Prosser, J. I., Embley, T. M., Wolden-

Kumari, S.K.S., Marrengane, Z., Bux, F., 2009. Application of quantitative RT-PCR to determine the distribution of Microthrix parvicella in full-scale activated sludge treatment systems. Applied Microbiology and Biotechnology, 83, 1135-1141.

Lane, D.J., 1991. 16S/23S rRNA sequencing. Nucleic Acid Techniques in Bacterial Systematics, 125-175.

Lapidus, A., Nolan, M., Lucas, S., del Rio, T.G., Tice, H., Cheng, J.F., Tapia, R., Han, C., Goodwin, L., Pitluck, S., Liolios, K., Pagani, I., Ivanova, N., Huntemann, M., Mavromatis, K., Mikhailova, N., Pati, A., Chen, A., Palaniappan, K., Land, M., Brambilla, E.M., Rohde, M., Abt, B., Verbarg, S., Göker, M., Bristow, J., Eisen, J.A., Markowitz, V., Hugenholtz, P., Kyrpides, N.C., Klenk, H.P., Woyke, T., 2011. Genome sequence of the filamentous, gliding Thiothrix nivea neotype strain (JP2T). Standards in Genomic Sciences, 5, 398-406.

Masella AP, Bartram AK, Truszkowski JM, Brown DG, Neufeld JD. 2012. PANDAseq: paired-end assembler for illumina sequences. BMC Bioinformatics 13, 31.

Meyer, R.L., Saunders, A.M., Blackall, L.L., 2006. Putative glycogenaccumulating organisms belonging to Alphaproteobacteria identified through rRNA-based stable isotope probing. Microbiology, 152, 419-429.

Nielsen, P.H., Daims, H., Lemmer, H., 2009. FISH Handbook for Biological Wastewater Treatment. Identification and Quantification of Microorganisms in Activated Sludge and Biofilms by FISH. IWA Publishing, London, UK.

Stoddard S.F, Smith B.J., Hein R., Roller B.R.K., Schmidt T.M., 2014. rmDB: improved tools for interpreting rRNA gene abundance in bacteria and archaea and a new foundation for future development. Nucleic Acids Research, 43, 593-598. 
99 Terada, A., Lackner, S., Kristensen, K., Smets, B.F., 2010. Inoculum effects on com- 